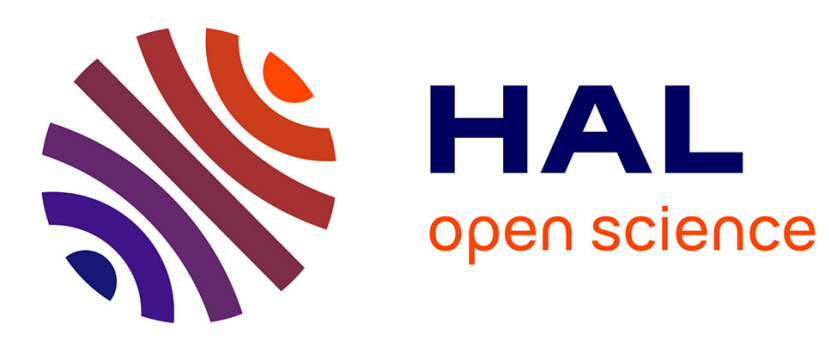

\title{
Les maisons à abside d'époque grecque archaïque de La Monédière, à Bessan (Hérault)
}

\author{
André Nickels
}

\section{To cite this version:}

André Nickels. Les maisons à abside d'époque grecque archaïque de La Monédière, à Bessan (Hérault). Gallia - Fouilles et monuments archéologiques en France métropolitaine, 1976, 34 (1), pp.95-128. 10.3406/galia.1976.1546 . hal-01938475

\section{HAL Id: hal-01938475 \\ https://hal.science/hal-01938475}

Submitted on 4 Feb 2020

HAL is a multi-disciplinary open access archive for the deposit and dissemination of scientific research documents, whether they are published or not. The documents may come from teaching and research institutions in France or abroad, or from public or private research centers.
L'archive ouverte pluridisciplinaire HAL, est destinée au dépôt et à la diffusion de documents scientifiques de niveau recherche, publiés ou non, émanant des établissements d'enseignement et de recherche français ou étrangers, des laboratoires publics ou privés.

\section{(ㅇ)(1) $\$$}

Distributed under a Creative Commons Attribution - NonCommercial - NoDerivatives| 4.0 


\title{
LES MAISONS A ABSIDE D'ÉPOQUE GRECQUE ARCHAÏQUE DE LA MONÉDIÈRE, A BESSAN (Hérault)
}

\author{
par André NICKELS
}

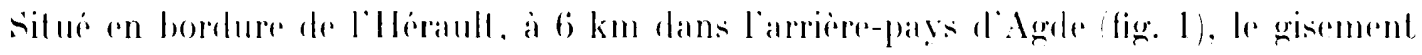

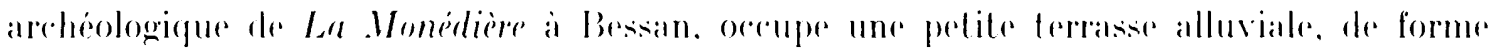
grossierement trapézoülate. dominant deune dizaine de metres la vallée inondable du

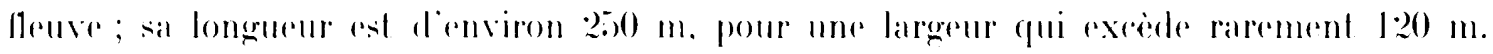
i la differene du nord, oì seole une faible dépression semble marquer les limites da site antique, les còtes est, sud at ourst presentent une rupture de pente assez nette (figr. 2).

Ce site est bien connu en Languedoc depuis sa première exploration en 1933) par J. Coulouma1. Sa situation exceptionnelle, à la tète de l'ancien delta de l'hérault, au

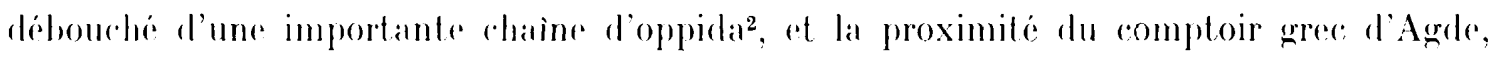
Agalhe, y ont provoque le developperment rapide d'un marehé indigène florissant des le

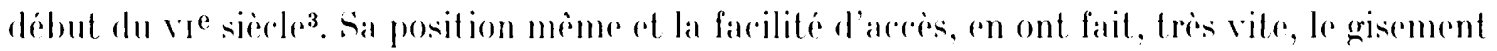
le plus prospeete en surface de lat régrion. Malgré l'abondanee et la qualite du materiel

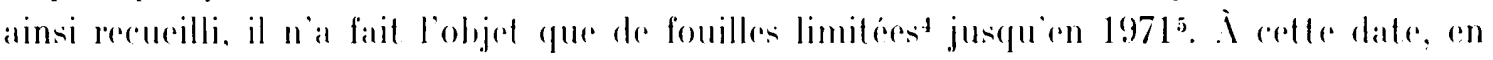

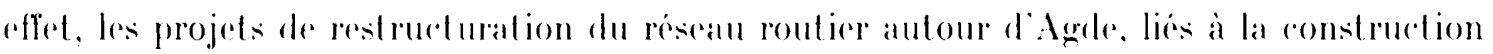
de l'autoroute $A$ ! et a l'aménagement touristique de cette partie du littoral, en faisant

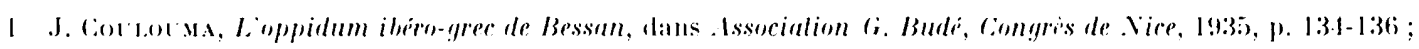

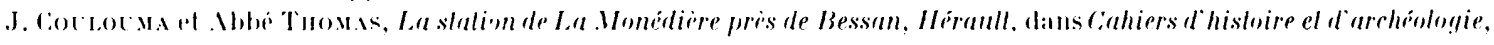
N1, 1936, p. (69)-71:3.

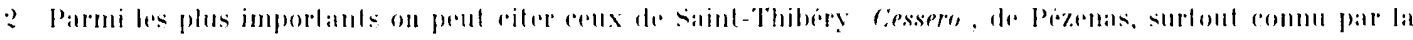

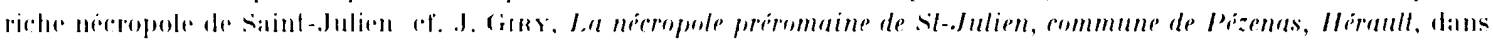

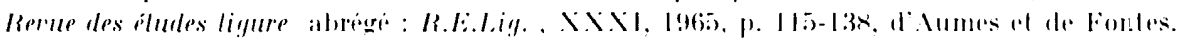

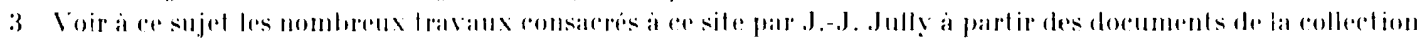

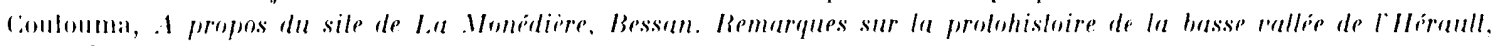

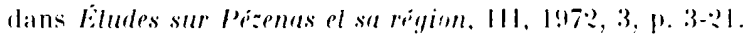

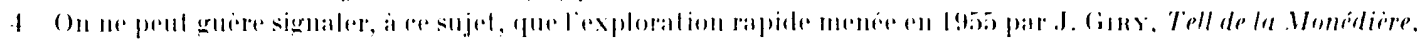

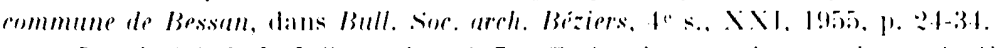

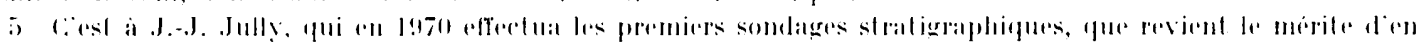

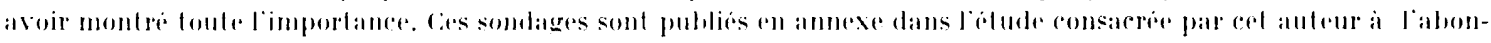

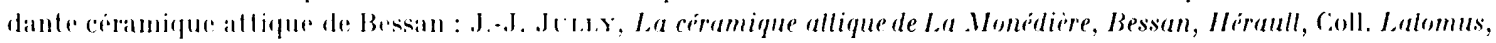
vol. 1:4, Bruxilles, 1973. 


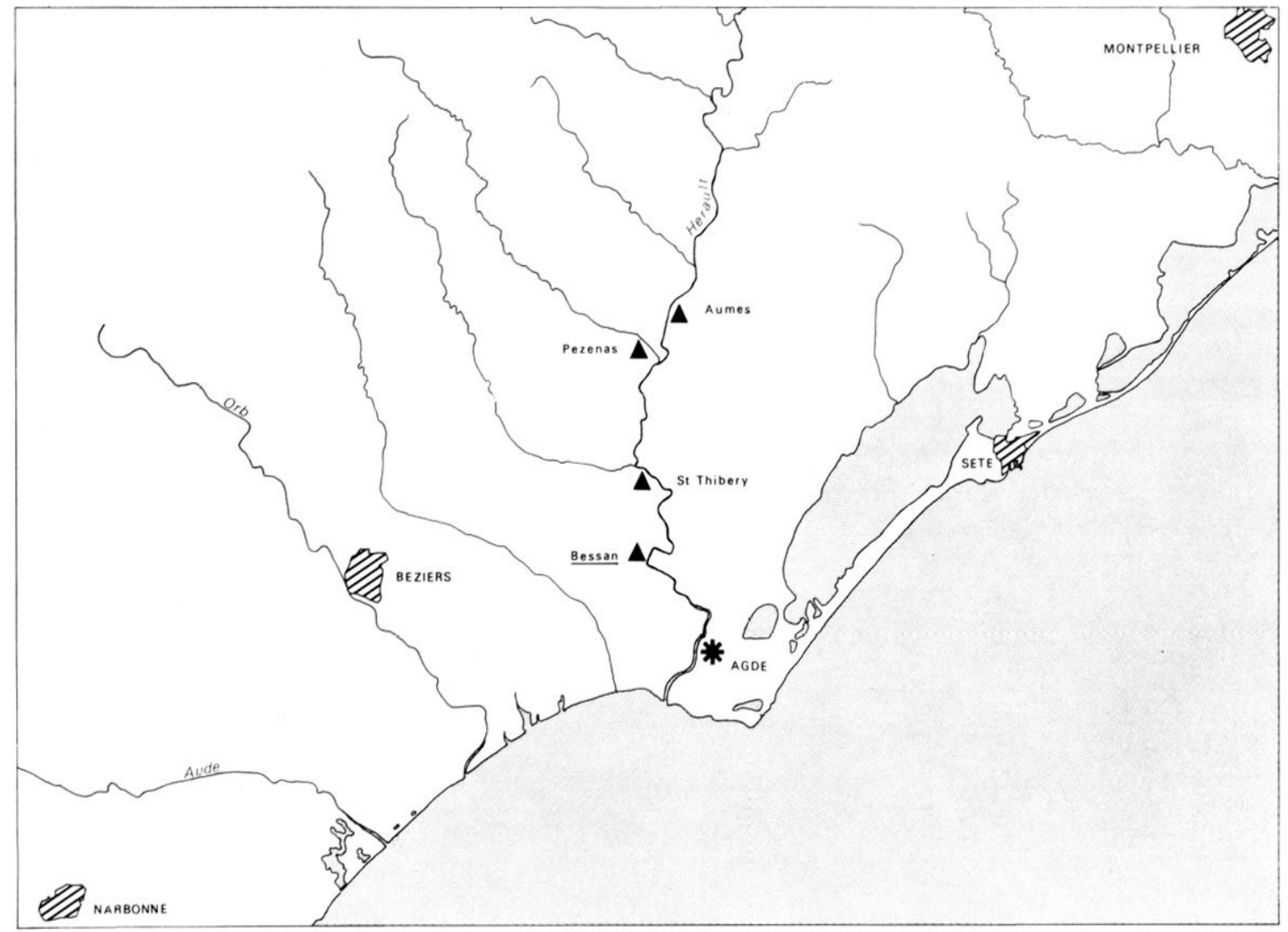

1 Principaux gisements premomains de la basse valled de lilleraull.

peser de lourdes menares sur son avenir, imposèrent la mise en rhantier d'une fouille de sauvetage, activement poursuivie depuis cette date

Les premiers sondages, en 1972 et 1973, eurent pour objet de procéder à l'ólude stratigraphique du site (figr. 3). En différents points, une sureression de niveaux d'orcupation. parfaitement individualisés, put ainsi être mise en évidence tandis qu'un mobilier varié était recueilli dans un contexte sùr. Dans l'un des sondages, fut notamment décourerte une intéressante fosse à offrandes, datée de la fin du troisième quart du vie siècles. qui présentait en association 21 vases coupe ionienne de type 1322 at ses imitations. plals:

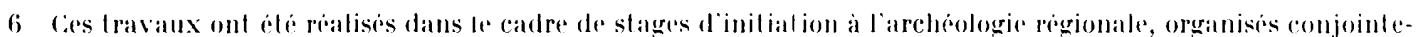
ment par la Direction regionale des Antiguites el le servire departemental de la Jeunesse ot des sporls, alve le soutien du Conseil général du departement de l’llerault. Gràce à ces aides substantielles, ume épuipe importante de jemmes a pu

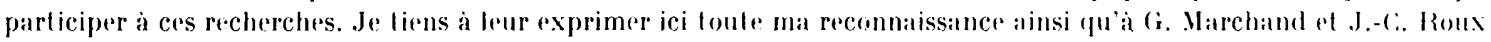
qui ont assuré la réalisation de la documentation graphique et photographique de celle dude. Mes plus chalenteux remerciements vont egalement à mon collegue P.-Y. Genly, dont le concours au niveau des travaux de terrain siest toujours révélé particulièrement eflicace, et surtout à G. Barruol, Directeur régional des Antiquités, qui par ses encouragements constants a permis de mencer à bien ce travial.

7 Les travaux furent effectues dans la parcelle 122, section C, feuille 1, du cadastre de Bessan, dans une vigne. qui devait être replantée sous peu.

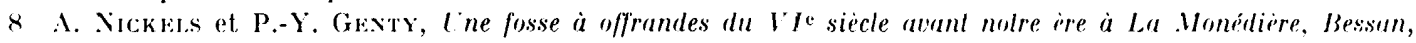
Iléraull, dans Revue archéologique de Narbonnaise, VII, 1974. 19. 25-57. 


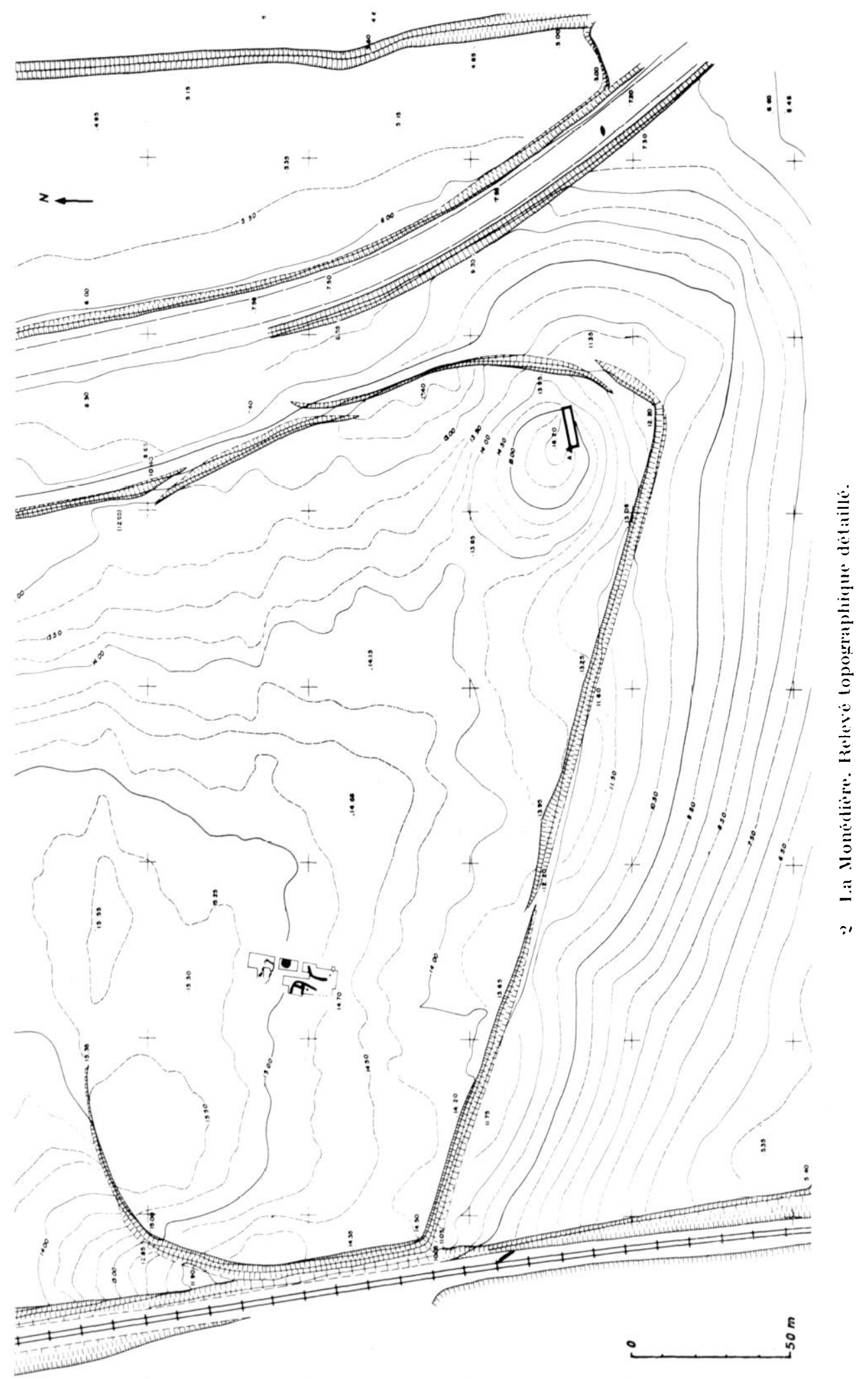




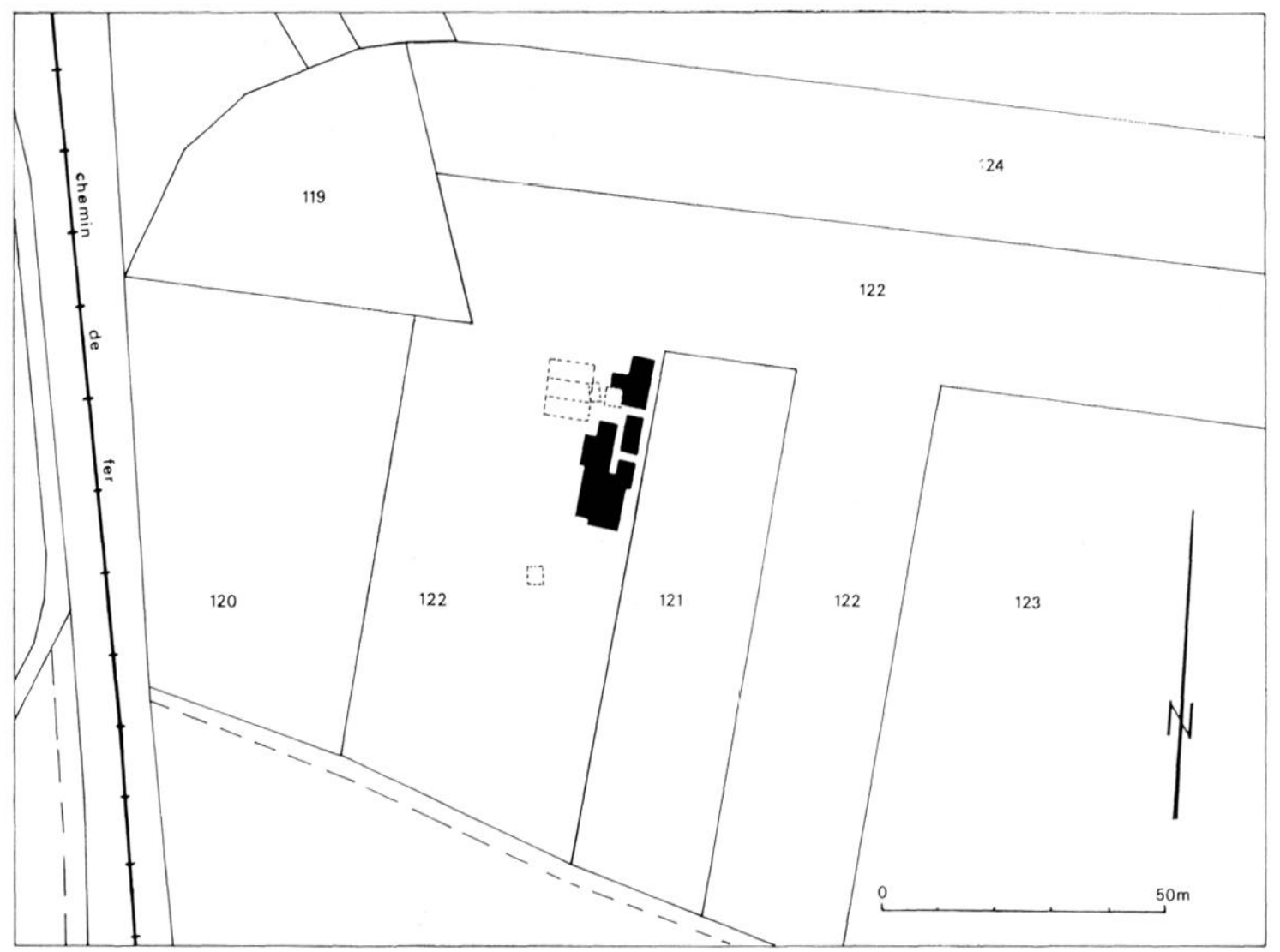

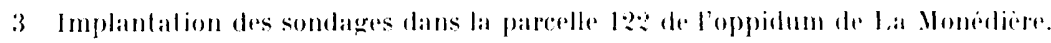

a marli, crateres a pied haut, coupelles indigrenes non tournées fous brises mais pour la plupart reconstituables en entier. lese travaux ont permis d'apporter d'utiles précisions: sur la chronologie des céramiques greegues d’oceident fabriquées dans be sud de la liaule: ils devront faire l'objet d'une etude particulière regroupant tous les ansembles stratigraphiques mis au jour au cours de ces trois années dre fonilles.

Ces résultats encourageants amenerent le développement. à partir du printemps 1974. d'une fouille plus étendueg, destinée a proceder à l'étude des restiges de constructions dont les recherches préliminaires avaient déjà localisé quelques tranes. Alors que dans less premiers sondages les vestiges de constructions edaient peu abondants of souvent tris détruits, la fouille de ce secteur révéla l'existener d'un vaste groupe de structures dans un etat de conservation exceptionnel. Si l'on veut lien tenir compte du fait que pour

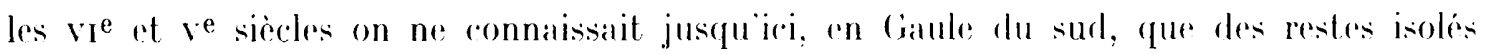
l'habitations dont on n'avait d'ailleurs que tres rarement le plan, on mesurera mieux l'importance de cette découverte. Ces structures appartiennent, en fait, à au moins deux

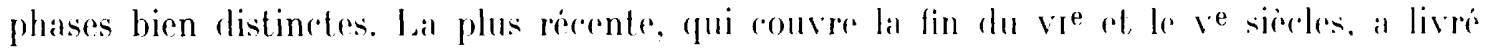
deux cabanes, de conception asse\% rudimentaire, qui, par endroits, recourent des vestiges

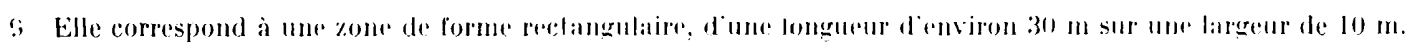


plus anciens, d'un lype nettement plus arolue. Afin de ne pas trop allongere reeter presentation. serules cess dernieress seront prises an compte irei.

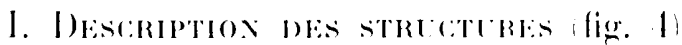

Trois ronstruetions ont ele raftarhés a la phase ancienne. Elles se distinguent de redles plus réeentes, non serulement par leur simple position stratigraphique, mats plus surement encore. par le reeours a un plan bien plus romplexe et par le soin tout particulier

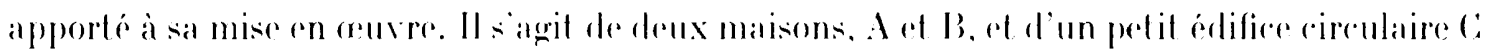
(ig. i).

\section{MASOX A.}

Cette habitation, an raison sans doute de la faible importance des remaniements recents dans ce sereteur. nous serait parvenue dans un etat de ronservation tout a fait exceptionnel, si un labour profond n'en avait detruit le tiers suld-ouest an cours de

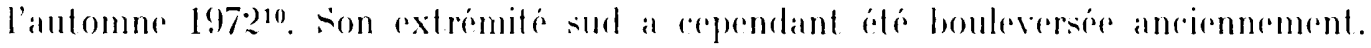

Le plan se empose dre deux parties bien distinctes: un rorps avant rectangulaire, prolonge all nord par une alside. Les dimensions completes de l'édifiere ne nous sont pats connues. Ciràce a la restitution du tracé de la courbe il est néanmoins facile

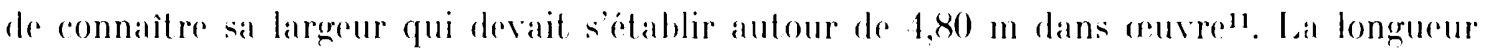
de la partie rectangulaire ne peut être précisée. Quelques blocs isoless qui subsistent dans le prolongement du mur est. indiguent cependant clairement qu'clle dépassait a m. (aes dimensions sont assez considérables et correspondent à une maison dont la longueur totale attrignail, el sans doute dépassait. 9 m. La soin apporté à l'aménagement intérieur est très remarquable'12. L'alside est, en effet, elle-mème sublivisée en deux pièces, d’inégale

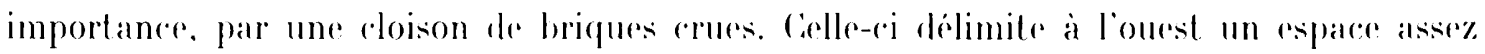
vaste. de 3.15 m sur $3 \mathrm{~m}$, flanqué à l'est d'un simple réduit, étroit at allongé, de $3 \mathrm{~m} \mathrm{de}$ long et d'un peu plus de 1 m de large. L'existence de trois pières bien individualisées est. confirmée par l'étude de la répartition du matériel. On constate, an effed, que l'essentiel du mobilier fin, attribuable avec certitude a la maison ${ }^{13}$. provient de la salle rectangulaire, noyau de l'habitation où, comme nous le verrons, se trouve le foyer. Le réduit oriental, au contraire, a livé une grande quantite de grains de bé brìlés. répandus à mème le sol, ainsi qu'un certain nombre de fragments d'amphores't4 : il pourrait correspondre a une sorte de reserve ou de cellier. Cese divisions sont encore alecentués par l'utilisation, pour te soubassement des derex parties, d'une terehnigue de construction differente.

10 Voir note 7, , . 96.

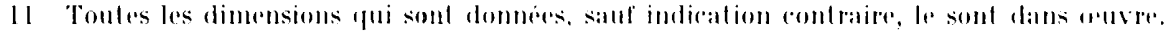

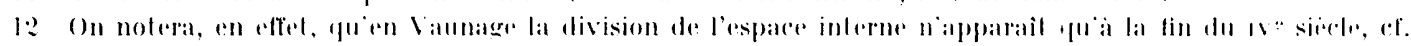

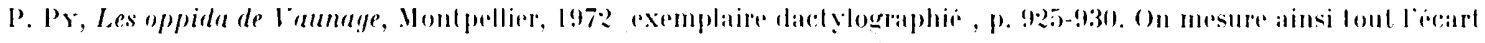
qui existe entre ces masons ef les constructious de lanreme-pays, meme a une date beaucoup plus tardive.

13 Voir infra, p. 113.

1.1 Voir infra, p. 113-114. 


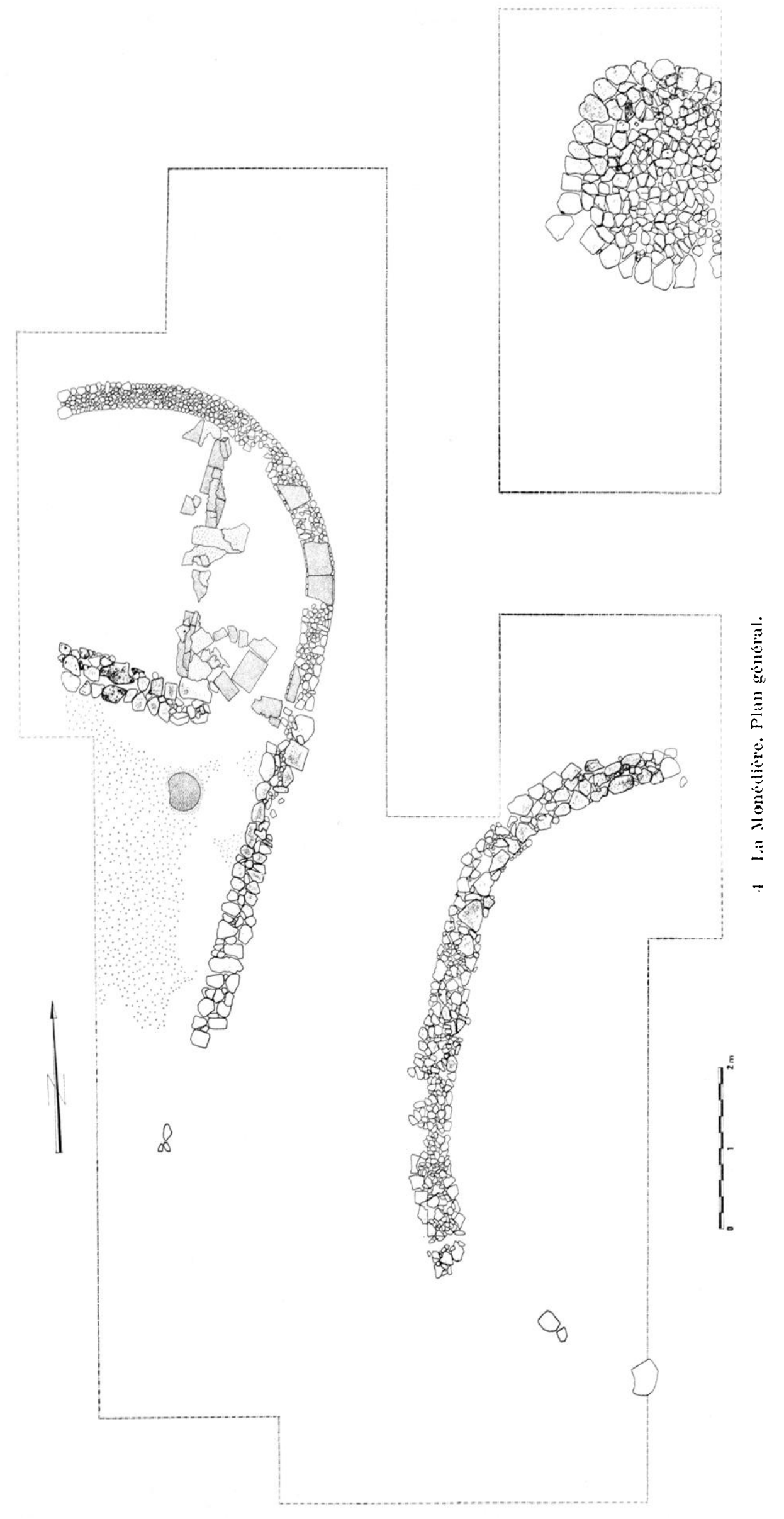




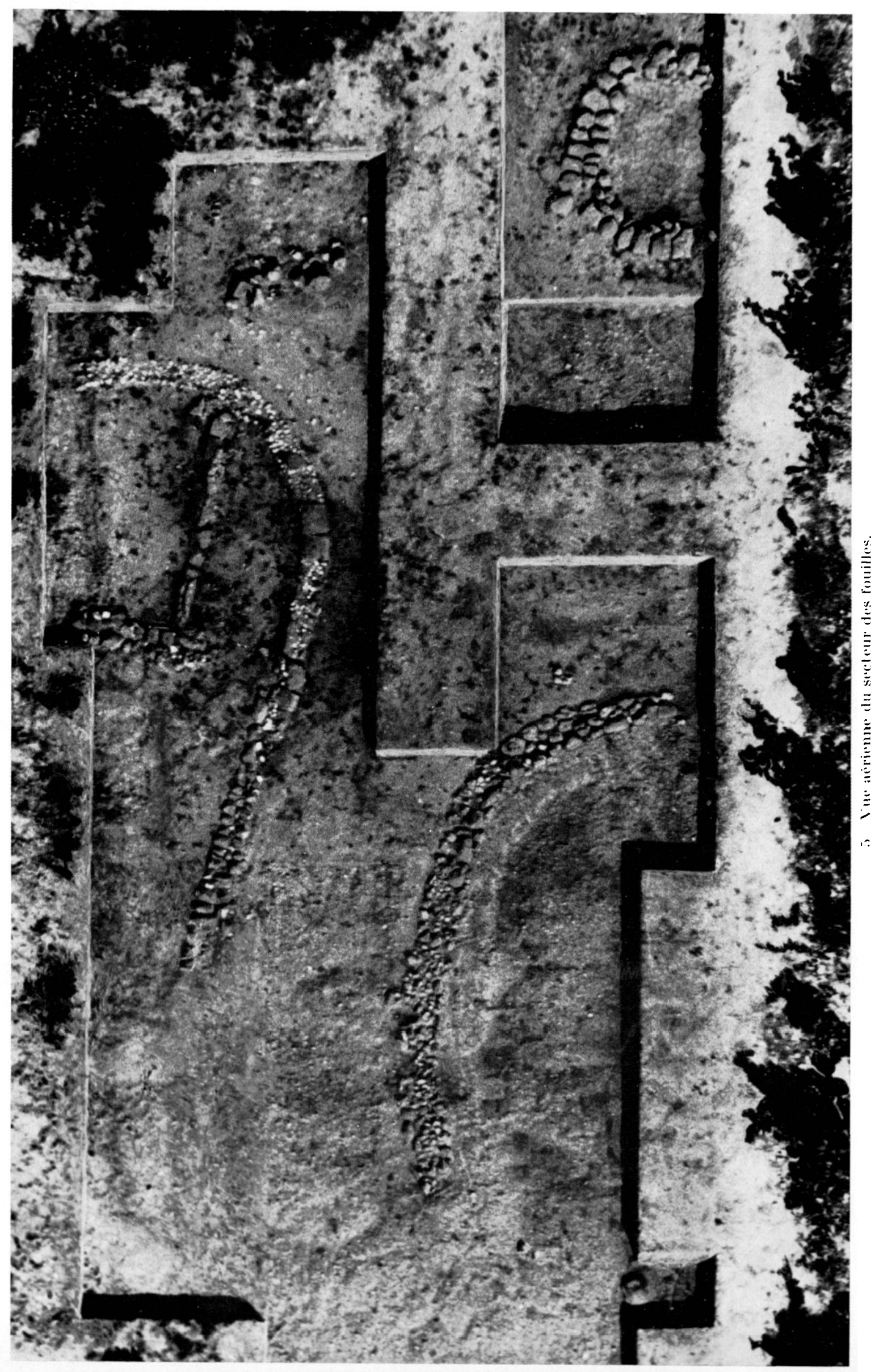




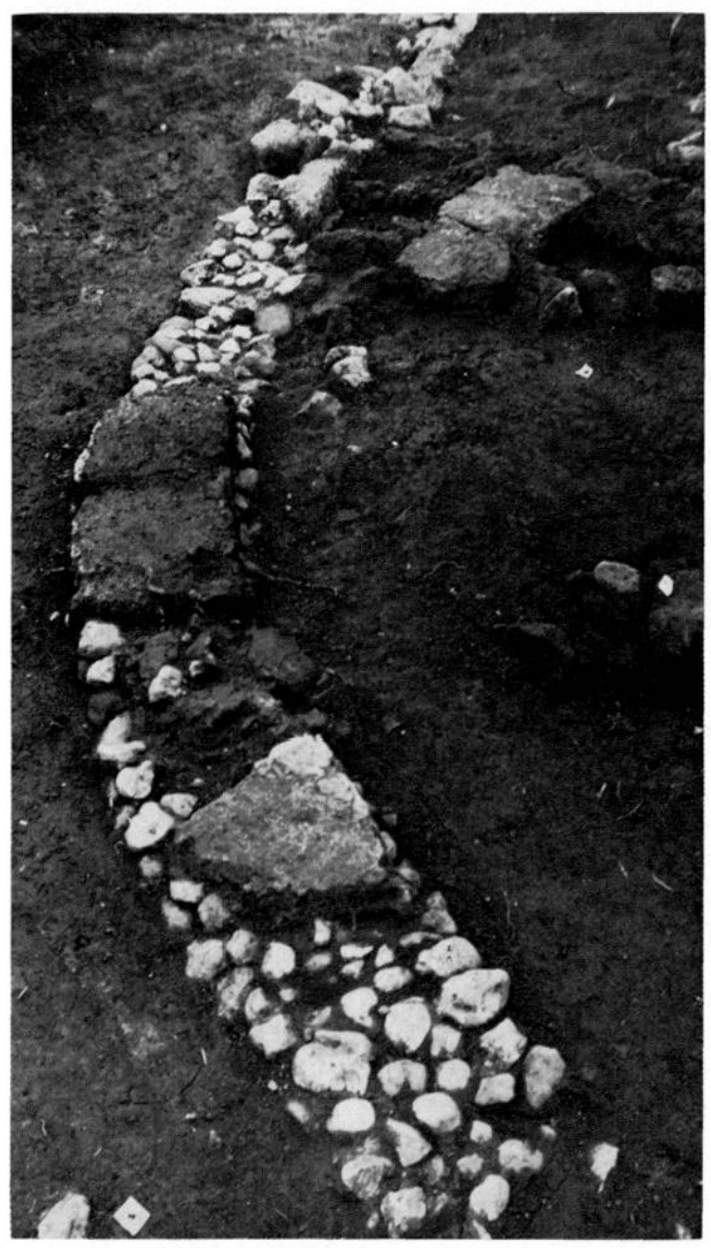

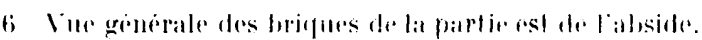

$\therefore$ Vile ginerale de lal doison.

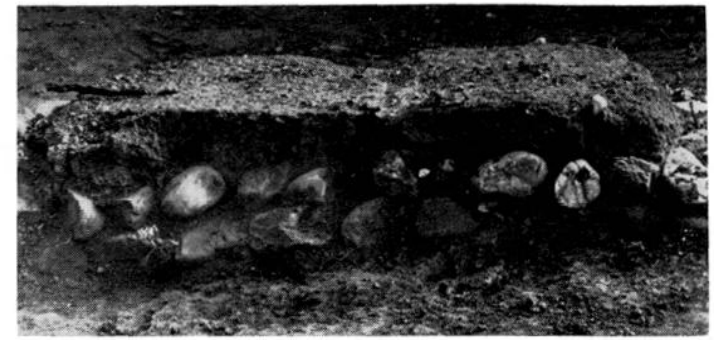

; Vur de delail des briques of dia sombassoment de analets do lathide.

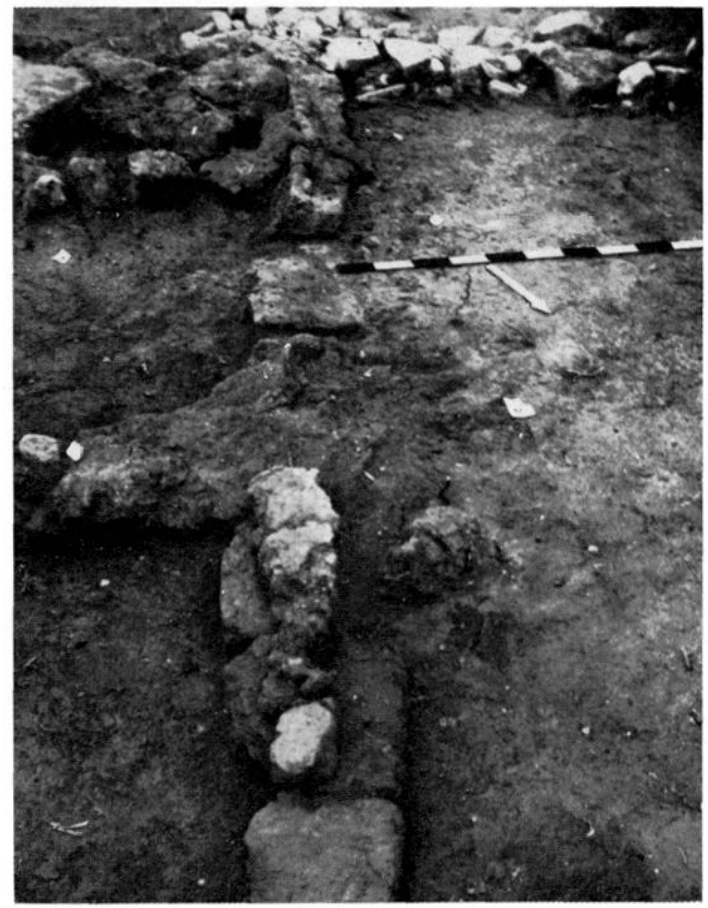

Le soubalssement de la partie quadrangulaire se caractérise par un appareillage soigne, ronstitué à peu près exclusivement de bloes de basalte ${ }^{15}$ de dimensions moyennes ${ }^{16}$, bien agencés, de facon à former des murs rectilignes. Leur disposition est assez variable. En certains points, un bloc plus important est place en boutisse et occupe toute l'epaisseur du mur ; dans dautres les morellons sont disposés còte a còte en deux ou trois rangées.

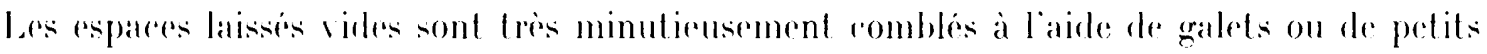
eclats de basalte. On remarquera que les deux murs est at nord, seculs conservés, nont pas la mème epaisseur. Le premier, là où il est intart, a une largeur d'environ 0,45 m alors que le second, qui marque la séparation avec l'abside, atteint $0,56 \mathrm{~m}$. I)ans l'angle

15 On insistera sur la presence, un remploi dans le mur, de plusienrs menles ou fragments de menles d'un type fres repandu an Premier Age du Fert.

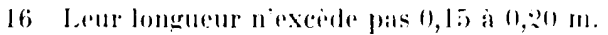


nord, ce dernier présente une ouverture, d'une largeur de $0.86 \mathrm{~m}$, immédiatement au contact du mur est. Il ne s'agit pas la d'une brèche arcidentelle, mais bien d'un véritable aménagement comme fo confirment les deux blocs, anormalement puissants, disposes en saillie dans le mur est, très exactement dans le prolongement du mur nord. Il y a la un souri manifeste de renforeement de celte partie de l'ouvrage. rendue plus fragrile par l'existence d'une ouverture. ()n preut ajouter que la seule lacune dans le parement interne du mur se trouve précisement à la hauteur de cess drux blocs et il n'est pas interdit de voir là l'emplacement d'un montant qui flanquait l'ourerture.

Le soubassement de l'abside à la différence du préédent. est constitué exclusivement de galets, disposes còte à còte en un lit très serré, de facon à former un mur courbe d'une largeur de $0,40 \mathrm{~m}$. Le ges galets utilises ont, en géneral, un diametre de 0,05 a a $0,08 \mathrm{~m}$ qui peut, dans certains cas, atteindre $0,14 \mathrm{~m}$. Là où l'our rage est bien conservé ils sont disposés en deux assises. les plus gros itant assez régulierement plarés an parement dans le lit inférieur, les plus petits en assurant te remplissage interieur et formant l'essentiel de l'assise superienre. Les mesures de nivellement. effereturese an divers points de l'edifiere, montrent. d'ailleurs, que la partife supérieure de cette assise roüncide trese exactement avere le niveall supérieur moyen des boes de basalle du corps avant. Il y a, dans les deux cas, le mème souci d'aménagement d'un plan de pose parfaitement horizontal, obtenu pour les murs de basalte par l'entassement des galets dans les moindres espares latissess libres entre le sommet des moëllons.

La maison A a livré plusieurs briques crues entieres, ainsi que de nombreux fragments, plus ou moins bien conservés. Ils proviennent tous de la partie nord-est et ont été retrouvés mêlés à une epaisse couche de terme noire at de cendres comprenant de nombreuses inclusions de particules de charbon de bois (figr. 6). L'épaisseur mème de cette couche semble indiquer que ce secteur de l'édifice a été détruit par un incendie qui, un provoquant Ieur cuisson partielle, peut seul expliquer leur exceptionnel etat de conservation. Les briques retrouvés an place sur le mur en fournissent d'ailleurs la premere en presentant régulierement une

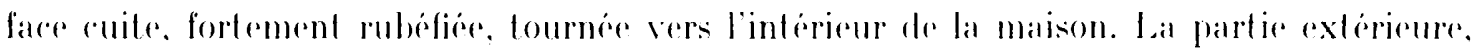

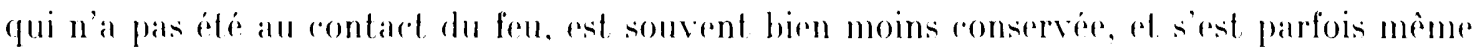
tolalement dissoute dans la trere environnante.

Ces briques appartiennent à trois ensembles différents : quatere lientre elles sont eneore en place sur le soubassement de galets du mur exterieur (fig. 7); une seule permed d'en connaître les dimensions: $0,42 \mathrm{~m} \times 0.33 \mathrm{~m} \times 0.09 \mathrm{~m}$. Ln grand nombre appartient à la cloison de direction nord-sud qui subdivise l'abside (fig. 8); aucune ne nous est parvenue intacte ef seule leur largeur. $0,34 \mathrm{~m}$, ef leur épaisseur, $0,09 \mathrm{~m}$, sont connues. Ieux rangées sont irei conservés ot sagencent suivant un systeme plein sur joint. le lif inférieur etant sans doute disposé transwersalement pour donner plus d'assise a la paroi. Il faut considererer a part un dernier groupe de quatere briques, provenant de l’interieur mème de l'abside. L'une d'elles, fortement rubetiée, Cetait intacte. Ses dimensions sont identiques à celles du mur extérieur. Deux autres, d'une largeur de $0.2 .2 \mathrm{~m}$ pour une longueur de $0.32 \mathrm{~m}$, correspondent peut-ètre a deux demi-briques. Toutes les trois ont eté retrouvées dans le prolongement les unes dess autres. un peru en arriere de l'areces à liabside, audquel elles 


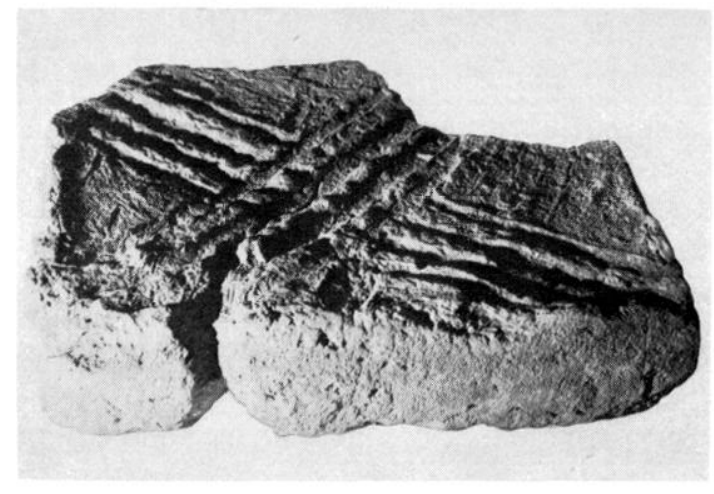

9 Briegue complete decomrerle an riemploi dans ume caballe indigrone.
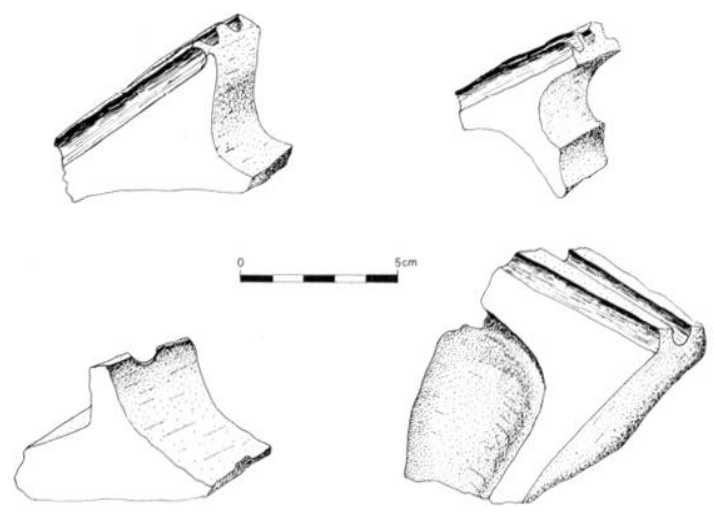

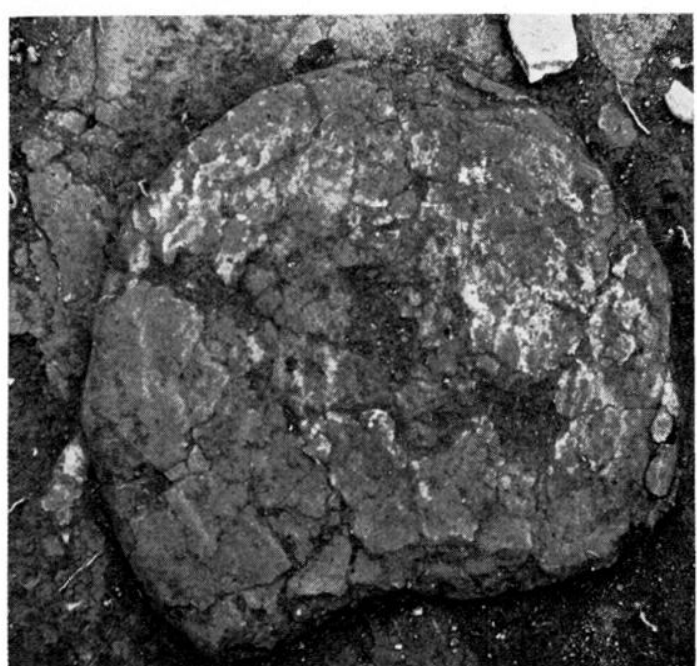

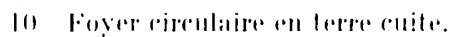

11 Elemenls diagre divers provenanl de l'abside.

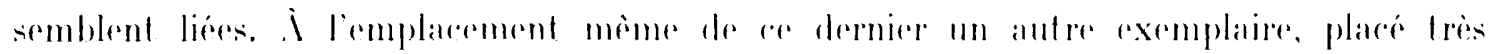
exactement dans le prolongement du mur nord, doit correspondre aux restes d'un seuil séparant l'alside de la salle arant.

Ine mention particulieme doit entin ètre faite pour une brique qui, si elle n'a pas étis retrouvé dans la maison A. doil néanmoins ètre prise an ensidération irei. an raison des précieux rensedgnements qu'elle apporte sur la forme ef la teehnique de fabrieation de

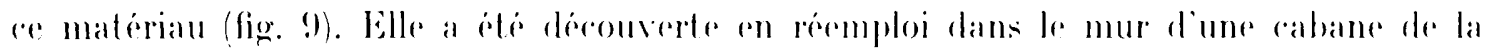
phase récente. Son interèt réside dans un etal de conservation tout a fait exereptionnel. dù sans doute à une forte cuisson. que nous avons, là aussid tout lieu de croire alceilentelle. ses dimensions sont de $0.44 \mathrm{~m} \times 0.33 \mathrm{~m} \times 0,08 \mathrm{~m}$. Ging de ses fares, la base et les quatre rotes sont parfaitement planes; fa fares suprepieure. all contraire, ast très irrégulière. Elle presente deux groupes de quatre sillons paralleles qui joignent ses angles opposés, en se recoupant an centre. Des marques semblables ont ite relevées sur des fragments provenant de labside. Elles sont liees all ststime de fabricalion de ces briques. confectionnées a l'aide d'un coffrage en bois qui sert de moulertz. La face irrégulière conserve d'ailleurs sur tout son pourtour un bourredet qui correspond a lapplication, par pression 
des doigts, de l'argile contre les parois de la matrice. Les sillons parallèles ont la même origine et correspondent également à des empreintes de doigts. Leur fonction était sans doute double : permettre une bonne répartition de l'argile dans les coins du moule mais surtout réer une surface assez irrégulière pour assurer une meilleure prise de larerile utilise e comme liant. Les dimensions de eette brique bien conservée. dont nous sommes sùrs qualle n'a pas subi d’importantes déformations, sont tres volsines de adles des exemplaires trouves en place et l'on peut considérer qu'elle en fournit te module le plus précis.

L'utilisation de ae type de matériau explique sans doute les différences d'épaisseur que l'on relive entre les soubassements des deux maisons, ainsi d'ailleurs que les variations au sein de la mème construction. Il n'est en effer. pas interdit de penser que si la disposition bout à bout a été adopté par la maison $A$, c'est peut-ôtre un agencement llane a flanc qui a prévalu dans le second cas. Il en va sans doute de même pour le mur séparant l'abside de la salle suld dans l'édifice A.

bans la salle rectangulaire, a quelques centimetres sous le niveau supérieur des blocs de basalte, a de degage un sol. parfaitement horizontal. sur lequel du mobilier cassé sur place a d'ailleurs éte retrouve. Il est ronstitué d'une fine couche d'argile, d'une épaisseur Ir 0,01 à $0,02 \mathrm{~m}$, nettement rubéfiée en surface. l)ans l'angle nord-est il arrive directement aul contact d'un disque de terre cuite, parfaitement circulaire, d'un diamètre de $0,47 \mathrm{~m}$. légèrement surélevé par rapport à l'aire environnante (fig. 10). Il doit s'agir là d'un foyer, comme semble d'ailleurs le confirmer la decouverte dans son voisinage immédiat, d'un support de vase en terre cuite en forme de boudin circulaire.

I a partie absidiale ne possédait qu'un simple sol de terre battue qui se trouve, toutefois. si l'on se réfère à la base de la couche de cendres, alu mème niveau que l'argile damée de la pièce rectangulaire.

Dans le réduit oriental de l'abside, conservés gràce à l'incendie qui ravagea ce dernier, ont été retrouves de nombreux fragments d'argile (fig. 11), adreidentellement cuits, présentant des empreintes de rondins de bois de de trames de roseaux dans des combinaisons diverses : branche assez irrégulière, d'un diamètre de $0.05 \mathrm{~m}$, grossièrement équarrie perpendiculaire à un grand rondin de bois. La branche est elle-même recouverte d'un réseau serré de roseaux d'un diamètre de 0,00 ; a $0,007 \mathrm{~m}$; rondins parallèles, de dimensions différentes, sur lesquels viennent s'appuyer perpendiculairement les roseaux; branche assez irrégulière, d'un diamètre de $0.04 \mathrm{~m}$, sur laquelle repose à nouveau une trame de roseaux. Le fragment présente une face plane qui fait un angle aigu avee cette dernière; roseaux entrecroisés.

Ces pièces, qui rappellent d'assez pres lese eléments de torehis retrouvés dans les cabanes d'époque préromaine en Languedor, doivent sans doute ètre mises en rapport avec la couverture de l'édifice. Si cette hypothese etait la bonne. ces vestiges fourniraient de très précieux renseignements sur son agencement. Its révèleraient, en effet, que l'ossature principale de la charpente était constituée de gros rondins de bois, sur lesquels venaient s'appuyer les branchages qui supportaient la couverture de roseaux.

Il ronvient enfin de signaler, dans le mème secteur, la présenere d'une fine plaque 
d'argile, de $0,008 \mathrm{~m}$ d'épaisseur, qui courrait une zone non négligeable du réduit en masquant en partie les briques de la cloison.

\section{Varsox P.}

Cat édifice, situé à l'est du premier, est beauroup moins bien conservé que ce dernier. Le seul mur qui en subsiste se compose d'une partie centrale rectiligne, grossierement parallèle à la maison A, prolongèe au nord at all sud par un troncon courbe. Ciràce a quelques blocs isolés, restés en place, son tracé exact peut ètre assez bien restitué. da mur est plus puissant que ceux de la maison $A$ et a une epaisseur movenne de $0,56 \mathrm{~m}$. L'appareillage est, la aussi, différent selon les secteurs considérés. La partie courbe est construite a l'aide de blocs de basalte d'assez grandes dimensions, d'une longueur qui lépasse souvent 0,$2 ;)$ m. Les moellons sont disposés en trois rangées parallèles, arec un comblement soigné de tous les interstices a l'aide d'éclats de basalte ou de galets, suivant une technique déja observée dans l'édifice précédent. Le mur droit, en revanche, est constitué de blocs plus petits, d'une longueur qui n'excerde pass $0.20 \mathrm{~m}$, et fait encore plus largement appel an remplissage compact de petits galets.

La présence d'une cabane plus récente, qui se superpose à cette construction, explique la disparition de toutes traces de son élévation. Tout semble cependant indiquer un recours aux briques crues comme dans la maison A. On y a, en effet, releve le même soin apportí à l'appareillage, ainsi qu'un souci identique d'aménagement d'une surface horizontale aussi parfaite que possible. He plus si aucun vestige de brique n'a pu ètre retrouvé dans ce secteur, la fouille a cependant révele l'existence, all voisinage des structures et immédiatement au-dessus des blocs, d'un terrain tres argileux qui doit rorrespondre a la dissolution de ce fragile matériau ${ }^{18}$.

le médiore etat de enservation of labsence dre tout elément de l'aménagement intérieur de rette maison, roison ou solp. an remdent toute restitution en plan délicate. On peut, en refet, opter. soit pour un ensemble a drux alsides tournées l'une vers le nord. l'autere vers le surl, soit pour une tres grande eonstruction. de direction est-ouest, dont nous n'aurions alors qu'une toute petite partie. Lat premiere solution, qui correspondrait à un minuscule corps central flanqué de deux énormes absides, est très peu vraisemblable. La deuxième. neltement préférable, n'est rependant pas non plus totalement satisfaisante. car elle implique un édifier aux proportions considerables dont la seule largeur dépasse $7 \mathrm{~m}^{20}$.

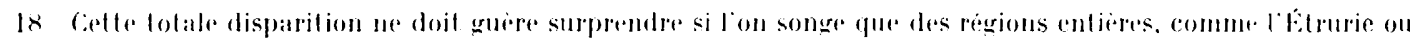

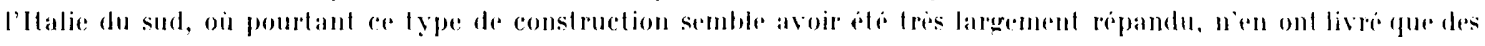
restes isolies.

19 A linterieur de la maison subsistaient cependant quelques lambeaux isoles de sols deargile damee, dont il na pas ble possible de clire avec certitude a quelle construction ils appartemationt.

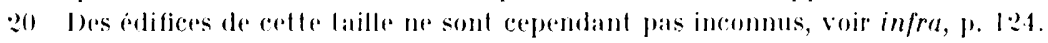




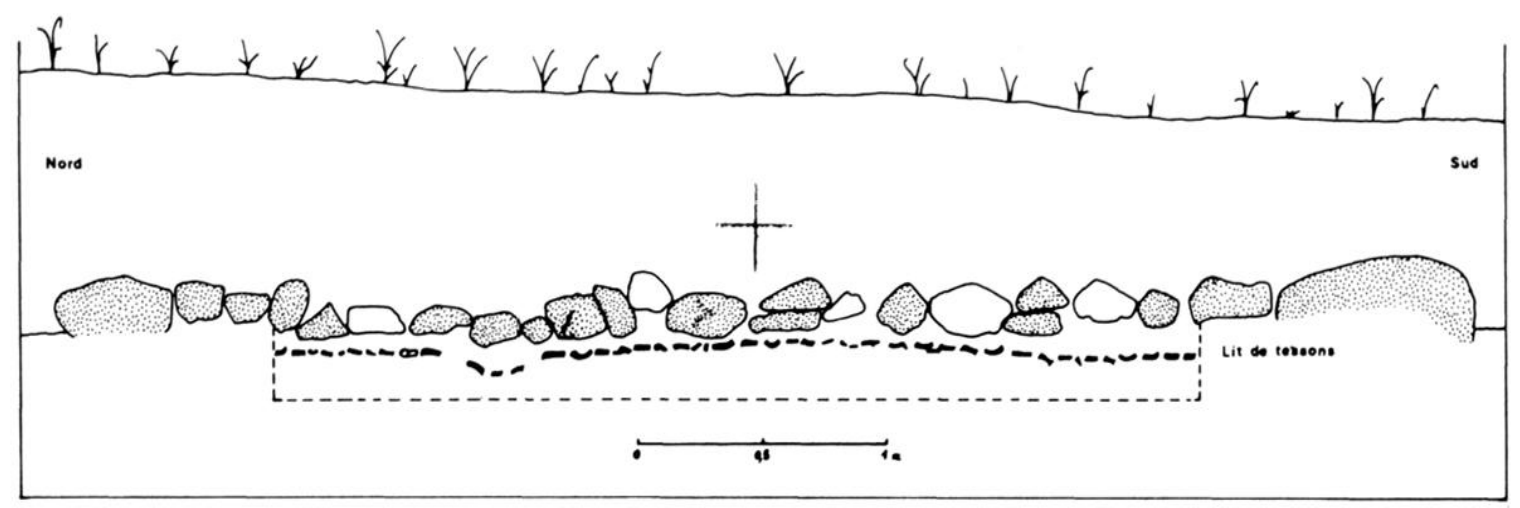

1:2 Coupe nord-sud de la structure circulaire.

Structure circelatre C.

Au nord des deux maisons a été dégagée une petite structure circulaire, d'un diamètre moyen de $2,85 \mathrm{~m}$, dont la destination reste encore imprécise. Sur tout son pourtour, elle est limitée par un parement de gros blocs de basalte ${ }^{21}$, en général de forme allongée, régulièrement aggencés de façon à tourner vers l'extérieur l'un de leurs petits côtés. L'intérieur, en revanche, est occupé par un remplissage dense d'éclats de basalte et de galets de dimensions moyennes, disposés en un seul lit (fig. 12). Là encore, le dessus des blocs aflleure partout à un niveau voisin et trahit la même recherche d'un plan horizontal que l'on a déjà pu noter précédemment. Cet aménagement doit correspondre au soubassement d'un édicule circulaire dont la conception d'ensemble n'apparaît pas clairement. Il n'est cependant pas interdit de penser que les gros blocs extérieurs servaient d'assise à un mur de briques crues, le pavement intéricur étant alors destiné à supporter un sol d'argile particulièrement soigné.

Ces trois constructions possèdent, comme on a pu le voir, un certain nombre de caractères communs, présence de parties courbes, puissant soubassement, soin apporté à l'appareillage, qui confèrent à l'ensemble une réelle unité. Ces structures ne sont cependant pas isolées. L'exploration rapide des parcelles voisines (123 et 124). menée en 1955 par M. l'abbé J. Giry, a en effet, permis de découvrir un important tronçon de mur courbe, d'une longueur de près de $6 \mathrm{~m}$, pour lequel aucune explication satisfaisante n'avait été proposée. Son épaisseur est de $0,55 \mathrm{~m}$, identique à celle des murs de la maison B. Le seul dessin, assez approximatif, qui en est conservé, montre un appareillage en tous points semblable à celui de nos constructions ${ }^{22}$. Il n'est pas douteux qu'il s'agit bien là de l'abside d'un édifice de très grande dimension, du même type que ceux étudiés ici. Le fait le plus intéressant est la localisation même de cette ancienne découverte, à plus de $150 \mathrm{~m}$ à l'est des fouilles actuelles. Cette observation implique qu'à une certaine époque, qu'il nous faut maintenant préciser, ces maisons à abside, loin d'être isolées, couvraient sans doute l'ensemble du site. 


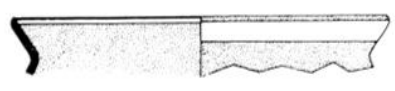

$1 \frac{M}{2}$
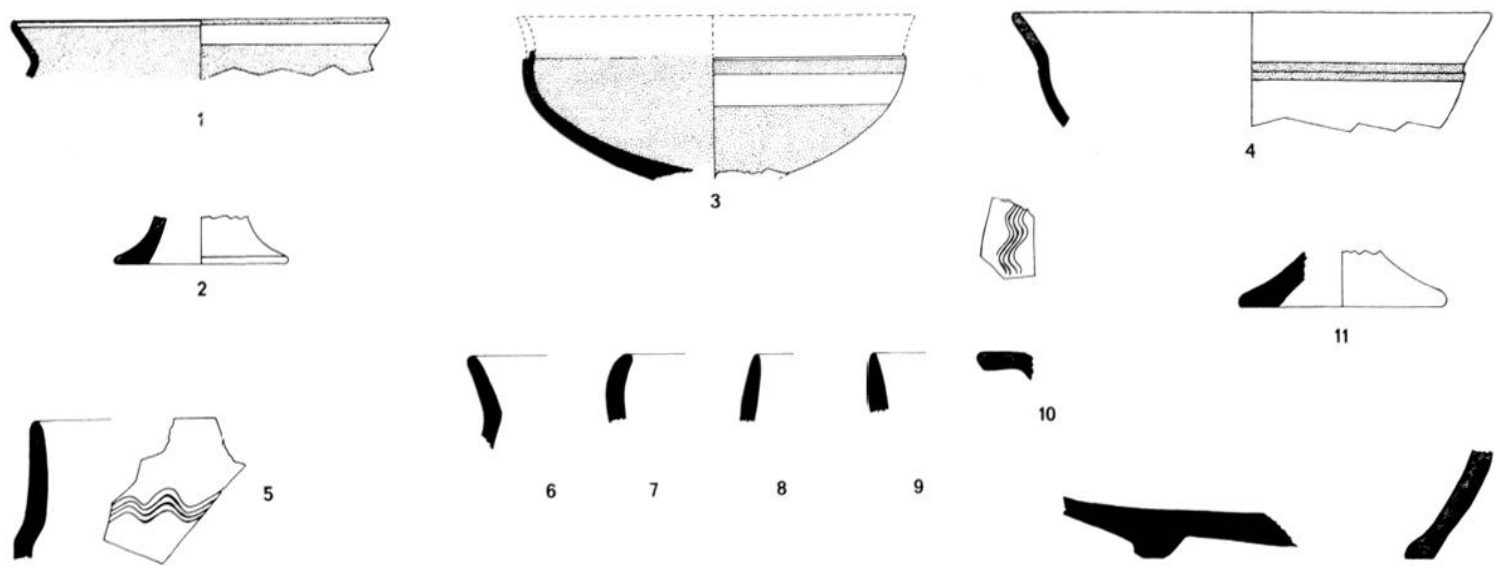

12
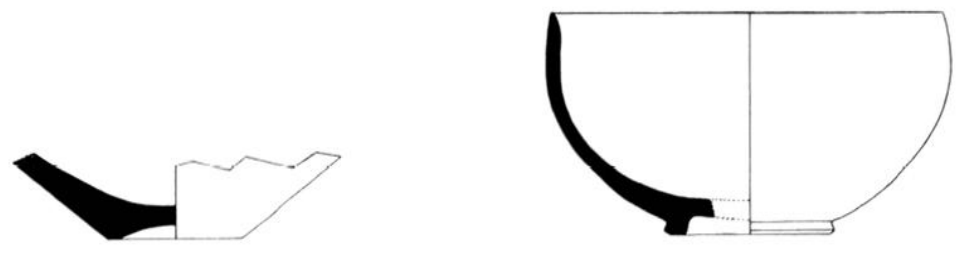

14

15
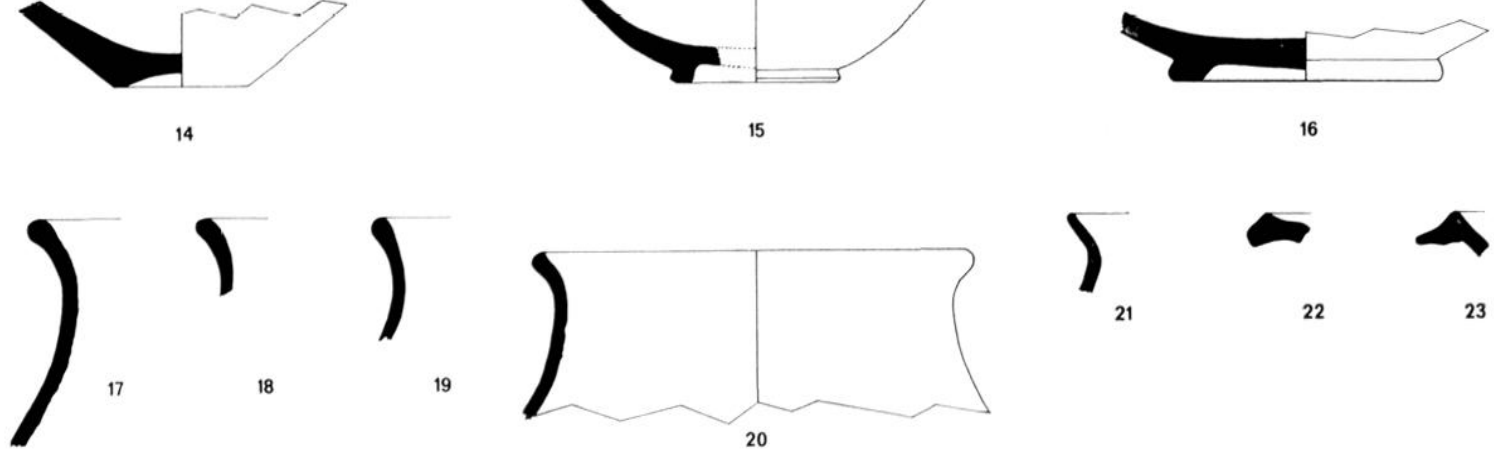

$\sum_{21}$
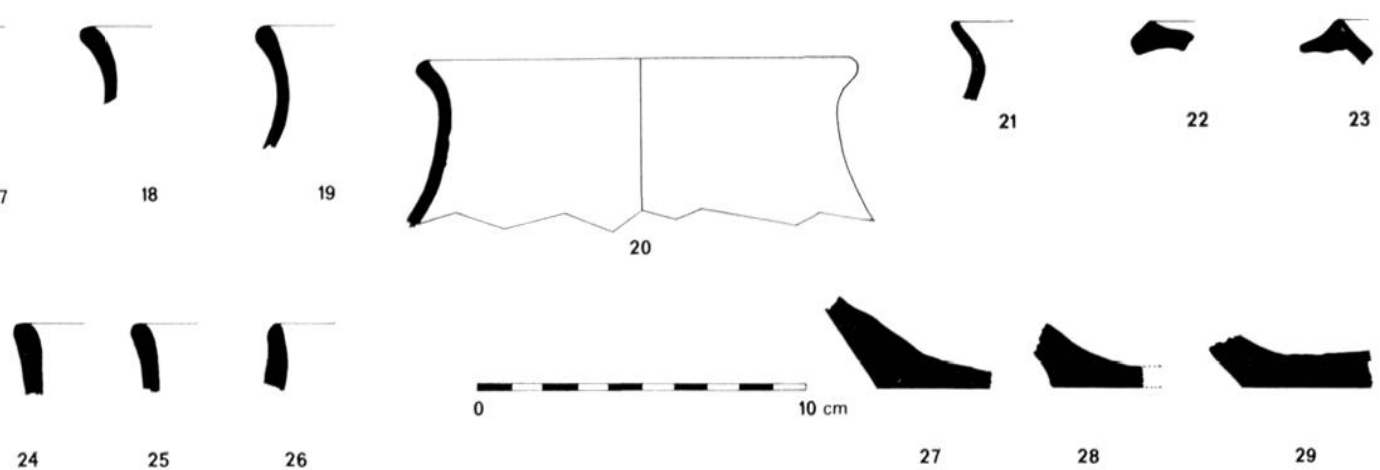

27

28

29
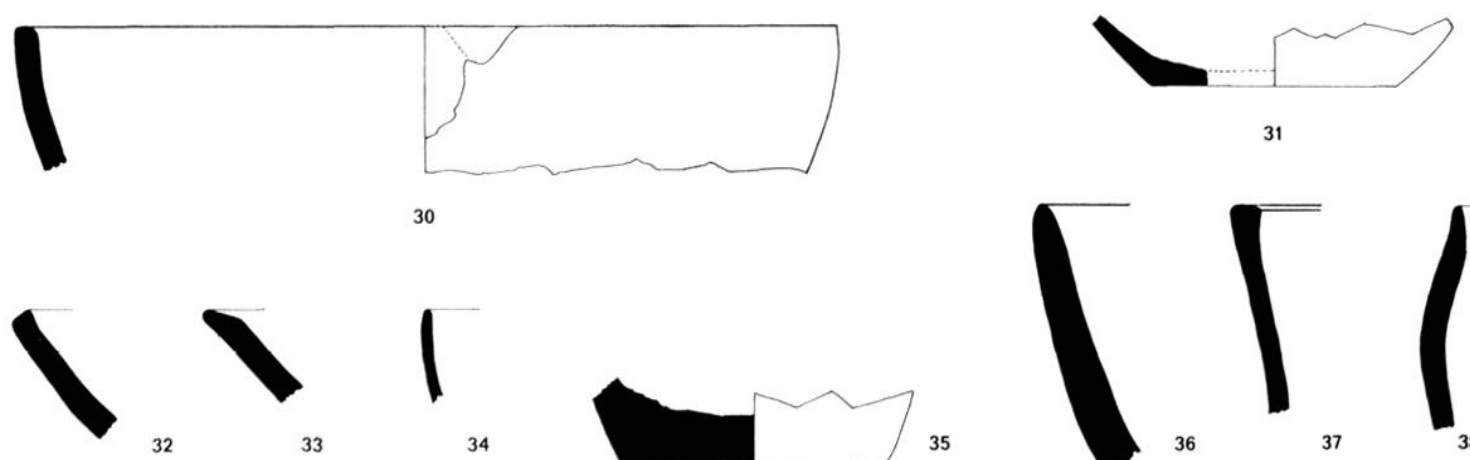

30
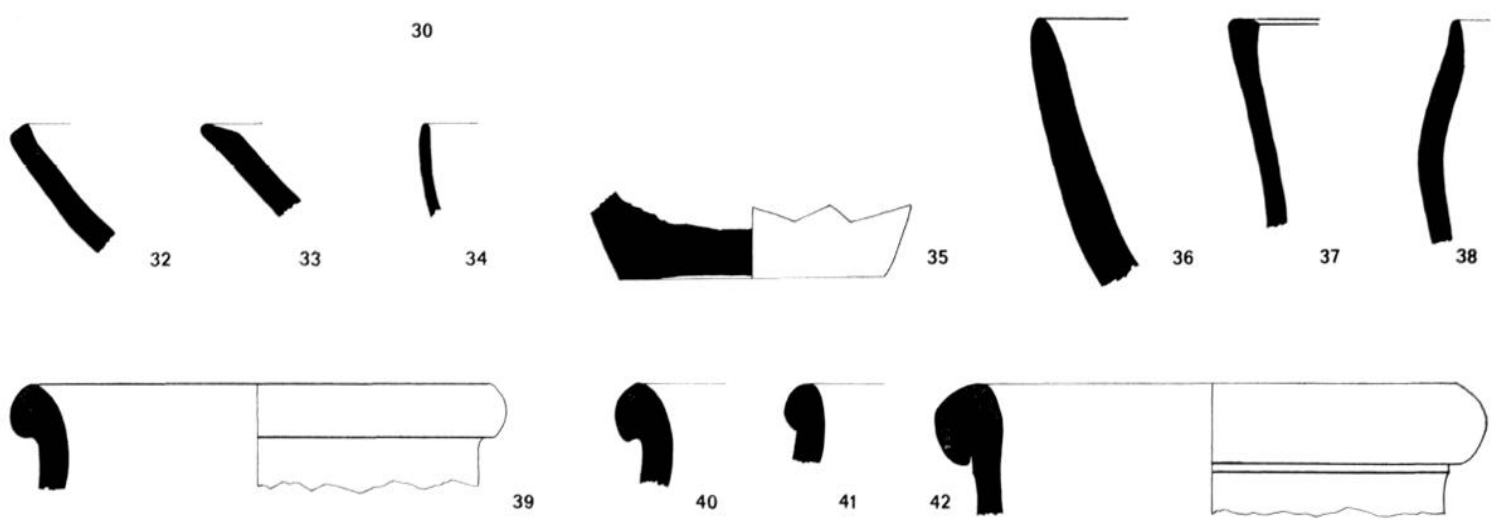

13. Maison A. Couches antérieures à l'edifice. 


\section{II. Étude de matérike hat datation des constrections}

L'exploration des maisons à abside a livré un mobilier considérable. Afin de lui garder toute sa valeur les zones de contar ${ }^{23}$, ou plusieurs ensembles sont susceptibles de se recouper, ne seront pas prisis en ronsidération ici. Ces secteurs sont particulièrement nombreux, en raison de la densité des réccupations dont ce site a fait l'objet durant une période assez courte. Lal conséquence en est une stratigraphie sourent complexe, aver de fréquents remaniements antiques partiels, qu'il est souvent difficile de raceorder entre eux, mais dont la suceession ponctuelle, en tel ou tel endroit, offre un réel intérêt. Compte tenu de cette situation nous envisagerons donc à part les différents ensembles, en éliminant à chaque fois less secteurs douteux.

\section{MaISON A.}

Conche anlérieure à l'édificalion de la maison (fig. 13).

Elle regroupe le mobilier provenant, d'une part, d'un sondage de $2 \mathrm{~m}^{2}$ effectué au centre de la partie quadrangulaire à l'endroit où le sol d'argile était parfaitement conservé et d'autre part celui recueilli en profondeur. à l'emplacement des murs. Les divers décapages révèlent que, dans tous les cas, l'on a affaire à une seule et même couche, très homogène, d'une épaisseur d'environ $0,20 \mathrm{~m}$. Elle sépare les fondations de l'édifice du substratum de galets qui se trouve là à une profondeur de $0,80 \mathrm{~m}$ par rapport au plan de campagne. Elle est constituée d'une terre assez meuble, pulvérulente, de couleur brun grisâtre, incorporant de petits galets, de plus en plus nombreux au fur et à mesure que l'on approche du terain vierge. L'extrême état de fragmentation de la céramique et la rareté des possibilités de reconstitution, indices d'une très grande dispersion du matéricl, révèlent que l'on a affaire à une couche de nivellement, profondément bouleversée par l'installation de la maison. Cie mobilier est varié :

a) Bucchero nero : plusieurs fragments ont été recueillis. Lát plupart appartiennent à des canthares; un seul semble provenir d'un vase fermé, sans doute une oenochoé. Il s'agit d'une céramique de qualité moyenne, qui ne différe en rien de celle déjà signalée à plusieurs reprises sur ce site $^{24}$.

b) Céramique grise monochrome (fig. 13, nos ¿) a 16) : avec plus de $36 \%$ elle constitue une tres grande part des céramiques fines de ce niveau. (On peut y reconnaitre les formes suivantes :

cratere caliciforme à pied haut ${ }^{25}$.

oenochoé,

23 Ainsi, bien évidemment, que toules les couches remanieses à une éporque récente.

24 Sur le bucchero en provenance de la Monediere voir : J.-J. Jot.s, . Wole sur la céramique elrusque de La Monédiere, Bessan, Héraull, el de .Montfo, Magalas, Héraull, ancienne colleclion .J. Cosulouma, dans R.E.Lig., XXVIII,

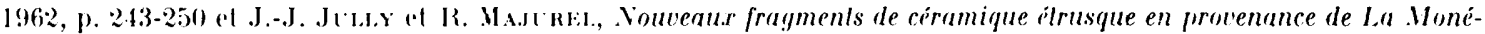
diere, Bessan, Héranll, dans R.E.Li!., XX.XVIII, 1972, p. :269-2\$6.

25) Ce type de vase, tres caracteristique, avec le plat à marli, du facies de la ceramique grise monochrome du

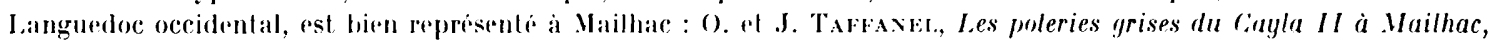


plats à marli lisse ou ondé, forme à laquelle plusieurs pieds annulaires semblent devoir se rattacher ${ }^{26}$,

coupes de types variés : hémisphériques, à bord plus ou moins convergents; les pieds correspondants, le plus souvent annulaires, peuvent être plats avec une légère dépression; - à bords droits; - carénées à décor ondé, forme rare sur ce site; à lèvre resserrée; - - imitant la coupe ionienne de type $\mathrm{B} 2$, comme le prouve la présence d'un pied en trompette très caractéristique.

Comme nous l'avons déjà noté par ailleurss ${ }^{27}$ la céramique grise monochrome de ces niveaux anciens présente une grande homogénéité. La pâte, de couleur gris clair, bien épurée, est finement micacée. Elle porte régulièrement une couverte noirâtre, assez épaisse, très fragile, qui confère à ce groupe une réelle originalité.

c) Céramiques à pâte claire ioniennes ou pseudo-ioniennes (fig. 13, nos 1 à 4) : les fragments appartenant à cette série sont peu nombreux et posent souvent un délicat problème d'attribution. Il est parfois difficile de distinguer ce qui appartient à la céramique grecque d'Occident ce qui est réellement importé de Grèce de l'est ${ }^{28}$. On peut cependant remarquer que pour les périodes anciennes les formes, et donc leur valeur chronologique, sont fondamentalement les mêmes. Dans le cas qui nous occupe, à côté de quelques tessons indéterminés, appartenant à des vases fermés, on peut signaler des éléments de trois coupes de type $132^{29}$ :

coupe ionienne à vernis noir, très brûlée, vasque assez profonde, parois fines, ressaut net au contact de la lèvre, bande réservée étroite, dans la zone des anses, recouverte d'un engobe blanc; rebord de coupe à pâte blanchâtre, brûlée, peinture brune altérée par le feu, ressaut net au contact de la lèvre. Exxécution négligée avec lèvre de hauteur irrégulière. Production de la céramique grecque d'Occident;

rebord de coupe à pâte jaune tendre et peinture noire. Parois très fines, lèvre convexe.

Il faut enfin y ajouter un pied en trompette très fin à peinture bleu-noir d'une coupe de même type.

d) Céramique commune tournée (fig. 13, $\mathrm{n}^{\text {os }} 17$ à 29 ) : le niveau antérieur à la maison a fourni en abondance plus de $57 \%$ de la totalité des céramiques fines --, une vaisselle commune à gros dégraissant, qui offre la particularilé d'être non pas morlelée, mais confectionnée au tour rapide. Ce groupe se distingue très nettement des vases non tournés par son homogénéité et par le soin apporté à sa fabrication. Les parois sont en effet remarquablement fines, avec une épaisseur qui, dans certains cas, est inférieure à $3 \mathrm{~mm}$. La pâte est dure el homogène, uniformément noire ou brune, avec un aspect légèrement feuilleté à la tranche. La surface, rugueuse, est très caractéristique. La couleur de l'épiderme peut varier entre le brun sombre et le brun rougeâtre, mais est le plus souvent noire. Le répertoire des formes est limité. On y rencontre à peu près exclusivement des urnes à col évasé.

Les autres formes, coupes ou urnes à bord rentrant, coupelles, plats, ne sont représentées que par des exemplaires tout à fait isolés. Les fonds correspondants sont en général plats, rarement

Aude, dans R.E.Lig., 1967, p. 245-276; à Pézenas : C. L.ıxas el A. Roßkнт, La nécropole de Saint-Julien à Pezenas. Fonilles de 1969 et 1970, dans Revue archéologique de Narbonnaise, IV, 1971, p. 1-33 cet à Bessan mème, A. Xıckłıs et P.-Y. GExтY, line fosse à offrandes..., op. cit., p. 52, fig. 12.

26 Ce plat est trés abondant à Bessan. La seule fosse a offrandes en a fourni huit exemplaires a peu pres complets.

27 A. Nickeis of P.-Y. (ikxty, op. cit., p. 31-33.

28 Si un certain nombre de productions, compte tenu de leur médiocre qualité, peut être attribué, sans grand risque d'erreur, à des ateliers occidentaux il faut, cependant, se garder de faire systematiquement de toutes les séries a pâte tendre des productions régionales. Dans les séries de qualité moyenne seule une analyse chimique permettra, sans doute, d'opérer une distinction rigoureuse.

29 F. Vilun el G. Var.tet, Lampes du VIJe siècle et chronologie des coupes ioniennes, dans Mélanges École française de Rome, I.XVII, 1955, p. 7-34. 
à dépression. Un travail de synthèse sur ce mobilier, jamais signalé, à notre connaissance, pour ces époques anciennes, est actuellement en cours et devrait permettre de préciser ces quelques observations.

e) Les amphores (fig. 13, nos 39 à 42) : les amphores étrusques sont les plus nombreuses ${ }^{30}$. Elles sont désormais assez bien connues ${ }^{31}$, pour qu'il soit inutile d'insister très longuement sur leurs caractéristiques. Les exemplaires de ce niveau semblent tous appartenir au type 3 de la classification de F. et M. Py, à col court, en forme de bourrelet semi-circulaire bien marqué, et à anses massives ${ }^{32}$.

Les amphores de type grec sont assez nombreuses ${ }^{33}$. Elles se distinguent des types massaliètes classiques par une pâte plus fine, mieux épurée et un dégraissant de mica beaucoup plus fin. La couleur de la pâte est variable el couvre toutes les nuances entre le beige et le jaune.

Les amphores massaliètes et puniques n'y figurent que sous forme de fragments isolés, sans aucune signification statistique.

f) La céramique commune modelée (fig. $13, \mathrm{n}^{\mathrm{os}} 30$ à 38) : elle est, de loin, la plus abondante, avec plus de $35 \%$ de la totalité des céramiques de ce niveau. son état de fragmentation est tel que l'attribution à des formes précises est souvent difficile. voire impossible. L'n certain nombre de bords appartiennent à des urnes; un seul présente un décor d'impressions au niveau du raccord panse-col. I.es fonds correspondants sont plats, avec parfois un léger étranglement au contact de la panse. On rencontre, en outre, des bols de différentes tailles, ainsi que des coupes à bords déversés. Deux fragments possèdent des tétons de préhension.

Cette couche de nivellement, permet, grâce à l'incorporation d'un mobilier caractéristique, de fixer un terminus post quem assez précis pour la construction de l'édifice qui la recouvre. Les éléments datables paraissent, en effet, tous antérieurs aux années 550-530. Si la date limite d'utilisation du bucchero nero en Languedoc a été, ces dernières années, quelque peu rabaissée par rapport au terme rigoureux fixé par F. Villard ${ }^{34}$, elle ne saurait, en aucun cas, dépasser le milieu du $\mathrm{vi}^{\mathrm{e}}$ siècle $^{35}$. Les coupes ioniennes de type $B 2$, autres fossiles directeurs majeurs des gisements archaïques languedociens, posent des problèmes plus complexes ${ }^{36}$. On s'accorde, en effet, pour attribuer désormais à cette série une période d'utilisation assez longue, qui peut atteindre la fin du troisième quart du vi ${ }^{\mathrm{e}}$ siècle, au moins en ce qui concerne les vases d'exécution négligée à la forme lourde, les exemplaires plus fins étant sans doute plus anciens. İ Bessan même, on peut ainsi signaler l'association, dans une fosse à offrandes découverte en 1973, d'une coupe ionienne importée avec une coupe pseudo-ionienne, imitant les modèles attiques du troisième quart du vi ${ }^{e}$ siècle, qui ne saurait remonter beaucoup au-delà de 530-52037. On notera cependant avec intérêt

$3053 \%$ du tolal du materiel amphorique.

31 Voir à ce sujet la récente mise au point de F. et .II. Pr, Les amphores ćtrusques de Vaunage el de Villevieille, Gard, dans Mélanges École fransaise de Rome, Anliquité abrégé : M.E.F.R..1. , X6, 1974, p. 141-254.

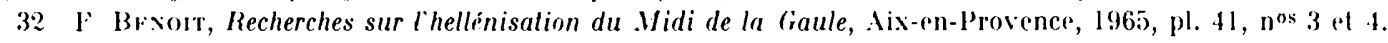

$3343 \%$ du tolal des fragments damphores.

34 F. Vuanu, Les canthares de bucchero el la chronologie du commerce étrusque d'importation, dans Hommage à 1. Cirenier, coll. Latomus, vol. LVIII, I962, p. 1625-1635).

35 Sur ce probleme de la datation du bucchero nero en Gaule du sud, voir en dernier lieu : C.. At.Bonf Lavant: L'épace étrusque du Ca!) d'Antibes, dans Hommage à F. Benoil, Bordighera, 1972, I, p. 300-326 ; J.-J. Jiı.L, . Youveaux fragments de céramique étrusque, op. cil., el surtout .I. Gnas, Les imporlations du l'I siécle avant .J.-C. a Tharros, sardaigne, dans M.E.F.R.A., 86, 1974, p. $79-139$.

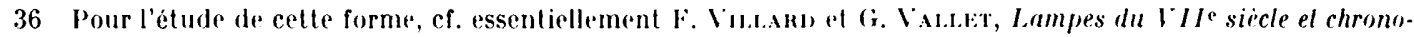
logie des coupes ioniennes, op. cil., p. 1625-1635.

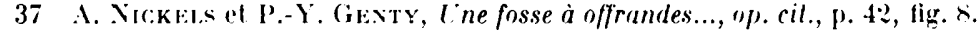




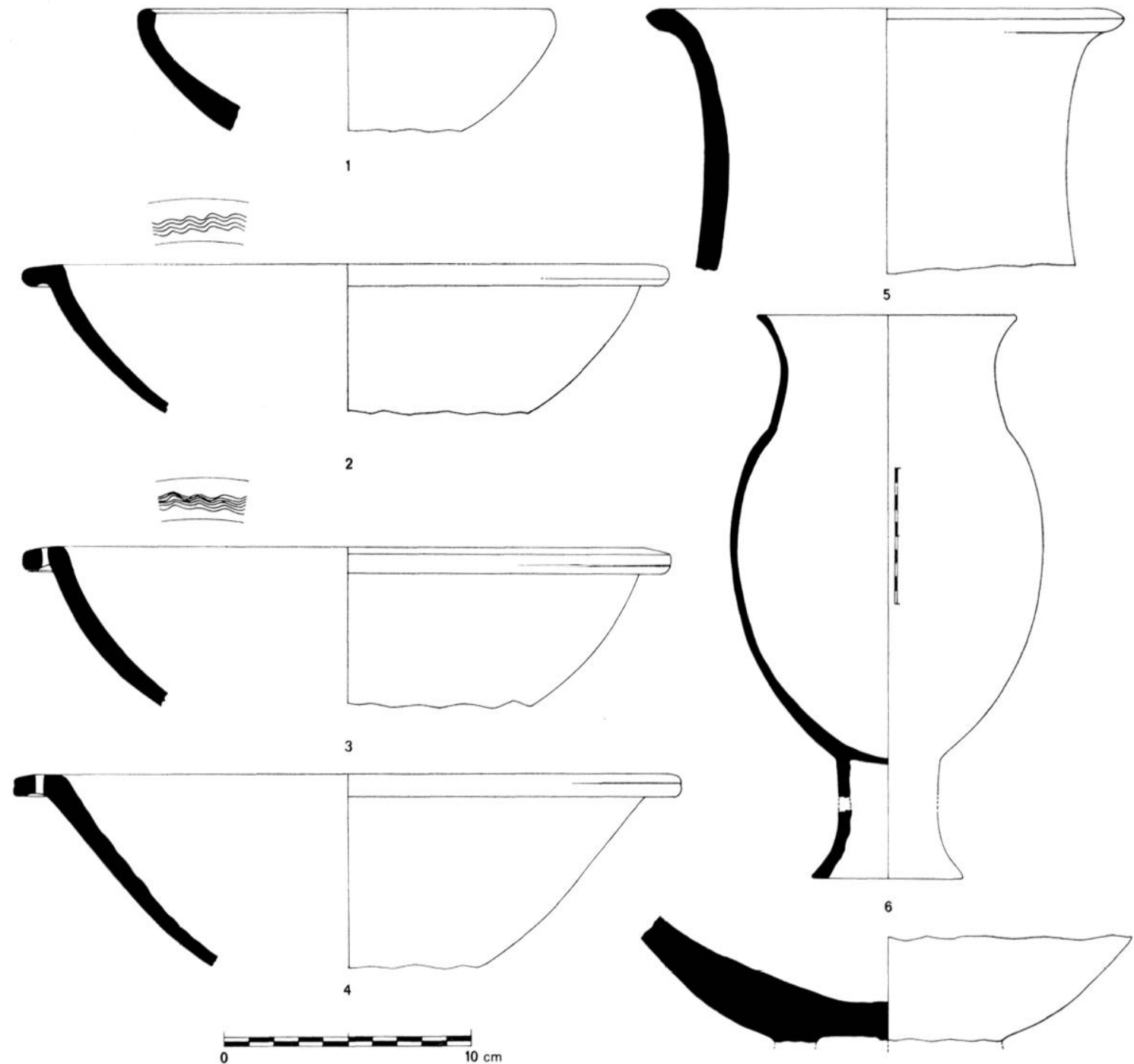

11 Ilaison . Nobilier contemponain de liedifice.

que les exemplaires de notre couche de nivellement sont, en général, soignés et ne semblent pas appartenir aux séries les plus tardives du type.

Un autre élément de datation non négligeable est fourni par l'absence, dans cette strate, de tout fragment attique. Sur un site qui en a livré par ailleurs un nombre exceptionnellement elevé ${ }^{38}$, le fait prend une réclle signification chronologique et invite, là aussi, à dater cette couche arant 50-50-3039. Le fait que les coupes en céramique pseudo-ionienne imitant ces mêmes types attiques ${ }^{40}$, très courantes à Bessan, fassent également totalement

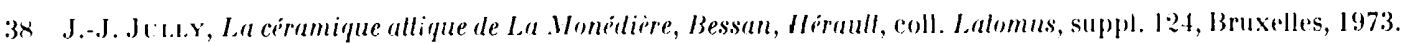

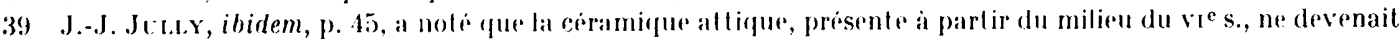
reollement abondante que dans le dernier liers du vies.

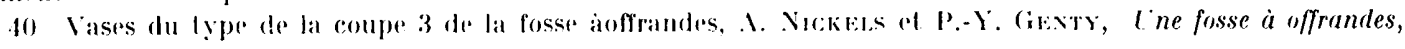
loc. cil., p. 41, fig. $8, \mathrm{n}^{\circ} 3$. 
défaut renforce encore cette observation. La répartition des différents types d'amphores enfin, avec une large majorité d'amphores étrusques, va dans le mème sens.

La parfaite concordance de ces quelques indications chronologiques permet donc de placer la construction dr la maison $\mathrm{A}$ dans les années 500-530.

\section{Mobilier contemporain de la maison (fig. 14).}

Si le matériel antérieur à l'édifice a pu ètre très bien isolé, il n'en ra pas de même de celui qui lui est contemporain. La principale difficulté provient de la présence, dans tout le secteur nord-est de la construction, d'une puissante couche de débris d'amphores qui masquait les structures. Il s'agit, comme nous le verrons, d'un véritable dépotoir dont les derniers lambeaux, dans la partie quadrangulaire, arrivaient directement au contact du mobilier de la maison elle-même. Par prudence, on n'incluera dans ce dernier que les fragments de vases trouvés bien à plat sur lo sol et qui offrent d'importantes possibilités de reconstitution ${ }^{41}$. On peut d'ailleurs noter qu'ils sont souvent brûlés, ce qui confère à ce groupe une certaine unité. Il s'agit exclusivement de céramique grise monochrome qui a pris une teinte jaunâtre à la suite d'une recuisson accidentelle. Elle porte une couverte sombre qui, le même, a viré au brun jaunâtre. On y relève les formes suivantes :

(ratere caliciforme à pied haut et creux (fig. 14, no 6 );

urne ou cratère a pied haut (fig. 14, nos 5) et 7). Un grand nombre de fragments se ratlachent a un col et à un fond annulaire massif sans qu'il soit possible de savoir s'il s'agit ou non du même récipient;

coupelle à bord replié vers l'intérieur (figr. 14, n¹);

plats à marli (figr. 14, nos 2 à 4). Au moins trois exemplaires, dont deux à décor ondé, proviennent du sol mème de la maison.

Ce mobilier suggère quelques remarques : en premier lieu, il convient de n'attacher aucune importance à l'absence, dans ce groupe, d'amphores, ce type de récipient n'ayant pas été pris en considération. en raison de la proximité du dépotoir, qui rend l'attribution de tels fragments au sol très incertaine. Bien plus intéressant est le fait que les six vases rassemblés appartiennent tous à la céramique grise monochrome qui semble bien constituer le mobilier type de la maison. On aura également remarqué l'absence de tout vase modelé ce qui, pour ces périodes anciennes, ne laisse pas d'étonner.

Les plats à marli ondé peuvent enfin, par comparaison avec le mobilier de la fosse à offrandes déjà signalée, fournir quelques indications chronologiques non négligeables. Cette dernière, bien diatée dans les années 50-520, contenait, en effet, 8 plats de ce type, dont un à décor ondé, et incite à placer le mobilier du sol de la maison dans la deuxième moitié du vi ${ }^{\mathrm{e}}$ ou les débuts du ve siècle ${ }^{42}$.

41 Cefle distinction a pu ètre operér assez facilement, compte lenu du fait que le dépotoir est constitué à pen pres exclusivement damphores, les ceramiques fines ny ibant représenteres que par des fragments isoles, en géneral aisement identifiables.

4:? Ine elude d'ensemble de celle forme est actuellement en cours. 

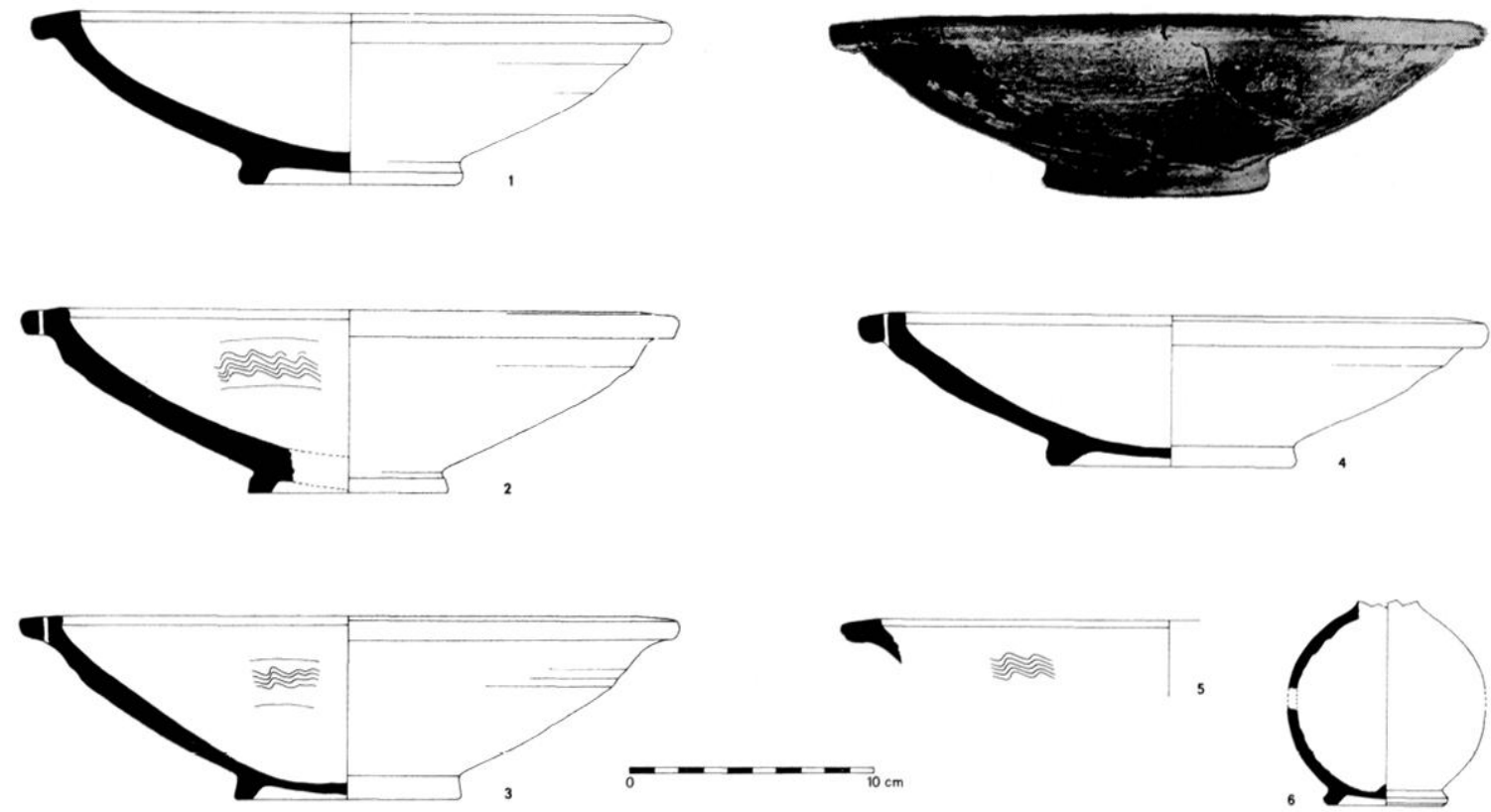

15 Maison A. Mobilier contempotain ou posterieur à l'idifice.

Couches contemporaines ou poslérieures à l'édifice (fig. 1) et 16).

a) A l'extérieur de la construction, à proximité du mur est, à un niveau voisin de celui du sol intérieur, a été découverte une zone cendreuse circulaire, d'environ $1,50 \mathrm{~m}$ de diamètre, qui contenait cinq plats à marli et un vase globulaire, tous en céramique grise monochrome (fig. 15). La position stratigraphique de cet ensemble est peu claire et il est impossible de savoir s'il est contemporain, ou légèrement postérieur à la maison. On peut toutefois noter qu'il est parfaitement scellé par le dépotoir d'amphores. Les plats sont tous du même type et possèdent un léger ressaut, immédiatement sous le marli, à l'intérieur de la vasque. La forme générale est très lourde et les parois épaisses. Trois d'entre eux sont décorés, sur le marli, d'une onde exécutée avec un peigne à quatre dents et deux ont un marli lisse sans décor. Tous portent des trous de suspension espacés de 16 à $18 \mathrm{~mm}$. La plupart de ces vases sont fortement brûlés et ont pris une teinte nettement jaunâtre. La couverte sombre dont ils sont munis a, quant à elle, viré au brun noirâtre.

b) Dans toute la partie nord-est de l'édifice s'étend l'importante couche d'amphores à laquelle nous avons déjà, à plusieurs reprises, fait allusion (fig. 16). Cette masse considérable, à certains endroits, atteint une épaisseur de plus de $0,20 \mathrm{~m}$, les fragments, souvent de très grande taille, se superposant directement les uns aux autres. L'abondance du mobilier et les nombreuses possibilités de reconstitution qu'il présente, semblent confirmer que l'on a affaire à un dépotoir. Son noyau d'accumulation primitif devait se trouver à l'extérieur du mur, directement contre l'abside, d'où le matériel a peu à peu été dispersé, en recouvrant les vestiges de la maison ${ }^{43}$. Rien ne permet de savoir si les premiers dépòts sont contemporains ou postérieurs à l'édifice. Sa durée d'utilisation ne peut être précisée, bien que la grande homogénéité du matériel milite en faveur d'une utilisation relativement courte. Compte tenu des importants travaux de restauration qu'il nécessitera, on se contentera, pour le moment, d'en donner un simple échantillonnage (fig. 16) :

43 On peut d'ailleurs penser que le mur, au moment de la creation du depotoir, avait encore une certaine hauteur, comme tend à le prouver la très inégale répartilion du mobilier, bien plus abondant à l'est qu'à l'ouest du mur. 

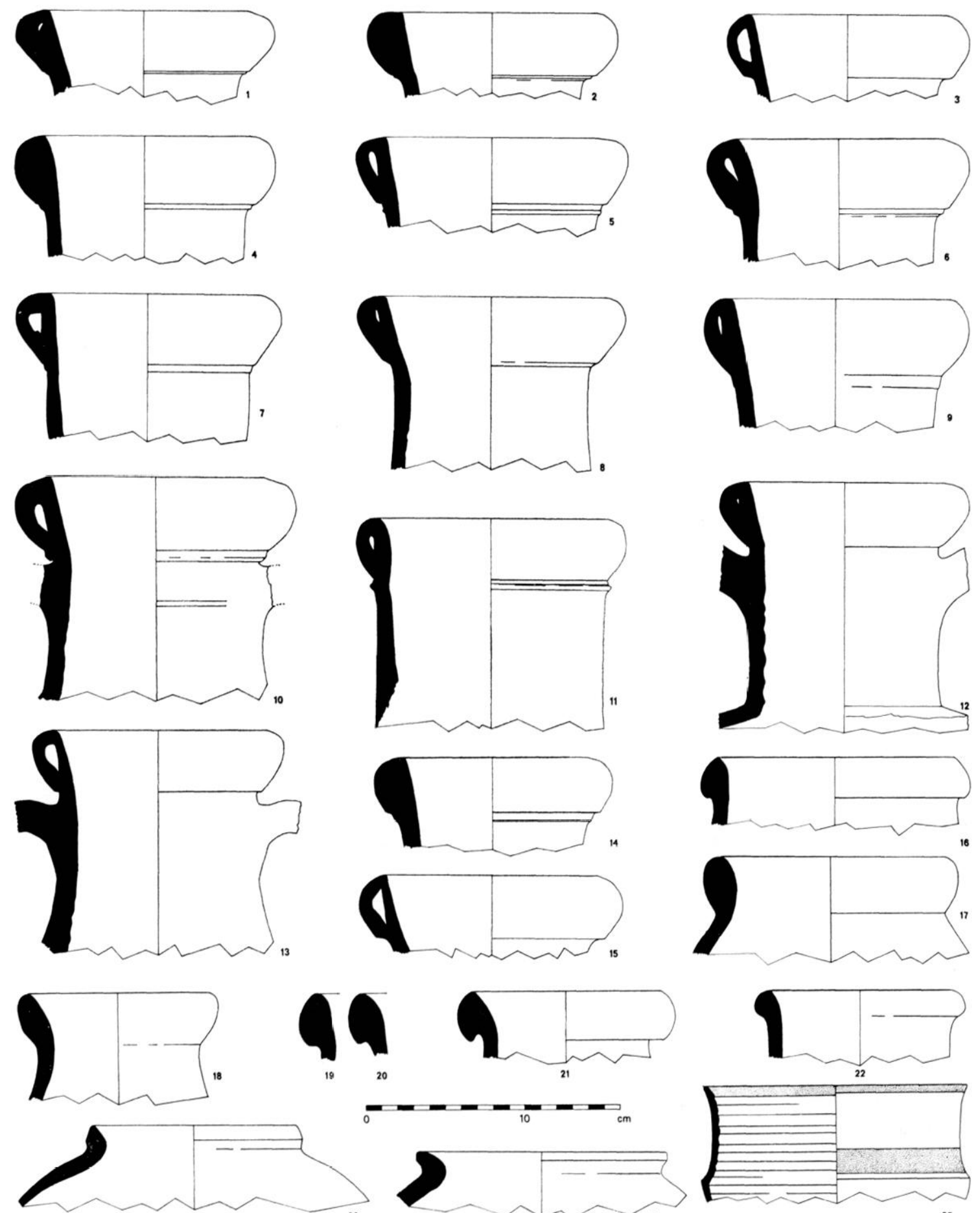

$-1-1-1 \mathrm{~cm}_{10}$
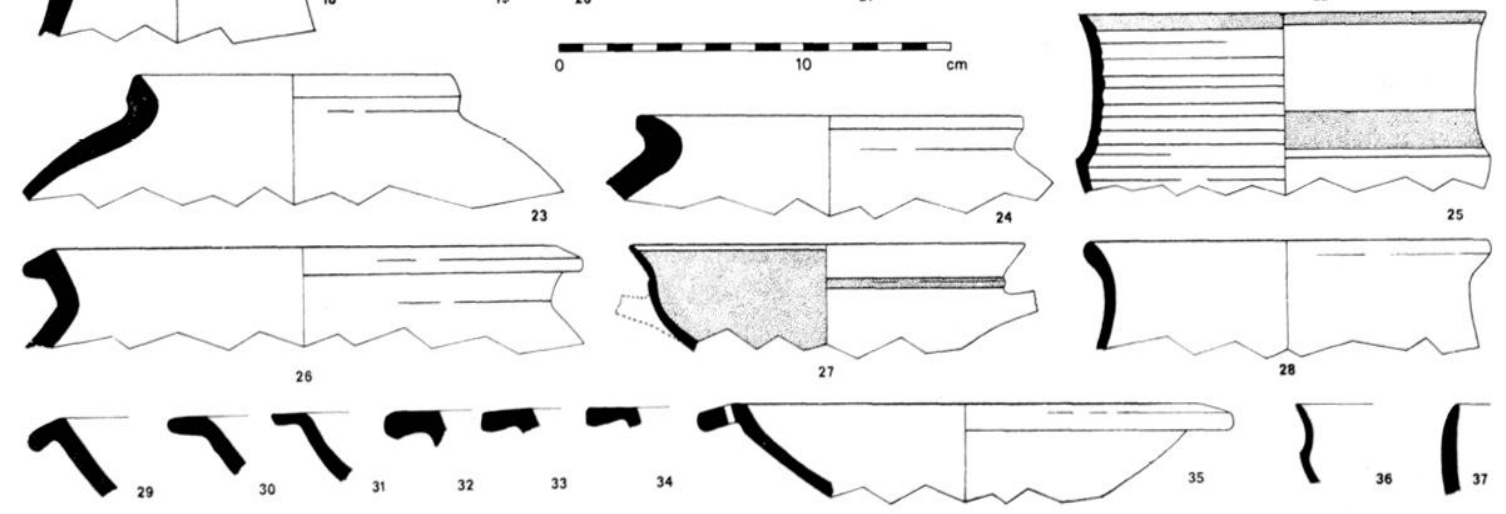

Y. I.

16 Maison A. Mobilier postéricur a la maison. 
amphores massaliètes ou de type grec, finement micacées:

amphores de type grec non micacées ( ${ }^{\text {os }} 1$ à 15 );

amphores étrusques (n ${ }^{\text {os }} 16$ a 22$)$;

amphores puniques (nos 23 et 24 ).

Les céramiques fines qui y sont associées sont enfin très peu abondantes (fig. 16, nos 25 à 36).

Cette couche ne peut, évidemment, donner que des indications vagues en ce qui concerne la date d'abandon de l'édifice. On notera cependant que la plupart des cols ont la lèvre repliée creuse des amphores massaliètes les plus anciennes, alors que les bords pleins ne sont que très faiblement représentés dans ce lot. Si les premiers, bien attestés dès le milieu du vi ${ }^{e}$ siècle, sont encore courants au ve siècle, les seconds ne semblent devenir récllement nombreux qu'à la fin $d_{u} \mathrm{vi}^{\mathrm{e}}$ et au début du ve siècle ${ }^{44}$. La rareté et la forme particulière des amphores étrusques ${ }^{45}$, ainsi que les céramiques fines isolées, qui y figurent, vont dans le même sens et semblent interdire de placer la destruction de la maison au-delà des premières années du ve siècle.

\section{MaIson 13.}

Nous n'avons ici aucun matériel attribuable avec certitude à l'édifice lui-même. D'un point de vue stratigraphique on peut, néanmoins, distinguer trois ensembles : une couche antérieure à la maison, une strate de destruction qui scelle les structures et enfin un niveau d'occupation, lié à une cabane indigène qui se surimpose à la première construction.

\section{Couche anlérieure à la maison (fig. 17).}

Elle s'étend sur une épaisseur d'environ $0,15 \mathrm{~m}$, jusqu'au substratum de galets et présente des caractéristiques absolument identiques à celles de l'édifice A avec notamment une céramique extrêmement fragmentée :

le bucchero nero reste assez rare avec des fragments appartenant exclusivement à des canthares;

la céramique grise monochrome est à nouveau très abondante et rassemble plus de $55 \%$ des céramiques fines de cet ensemble (fig. 17, nos 4 à 8 ). L'éventail des formes est le même que précédemment avec des coupes à bords convergents, des plats à marli, un cratère à pied haut, et des rebords d'urnes ou de cratères. Le seul élément original est un fragment de gobelet caréné ${ }^{46}$;

dans la céramique à pâte claire, ionienne ou pseudo-ionienne, il convient de ranger un fragment de coupe ionienne à vernis noir de type $\mathrm{B}^{47}$, plusieurs éléments de coupes très fines, sans doute de même type, et enfin quelques tessons indéterminés, décorés de bandes brunes ou rouges ( $\mathrm{n}^{\mathrm{os}} 1$ à 3 );

la naisselle commune lournée est, ici, plus rare que dans la couche sous-jacente ì l'édifice $A$ et

41 11. Pr. Les oppida de launage, Gard (fouilles 19:58-1968), Montpellier, 1972 exemplaire dactylographic, p. $632-635$

45) I. PY ol V. PY, Les amphores étrusques de Vaunage et de lillevieille, Gard, dans M.E.F.R.A., 86, 1974, p. 141-2.44.

If Cette forme paraît assez, rare à Bessan. Voir à ce sujet l'étude qui y a été consacrée par J.-J. Jut.t.Y al Y. Solntr, Les gobelels gris carénés, fails au tour, à l'Age du Fer languedocien, dans Hommage à F. Benoil, I, Bordhigera, 1972 , p. $217-244$.

47 Voir note :29, p. 110. 

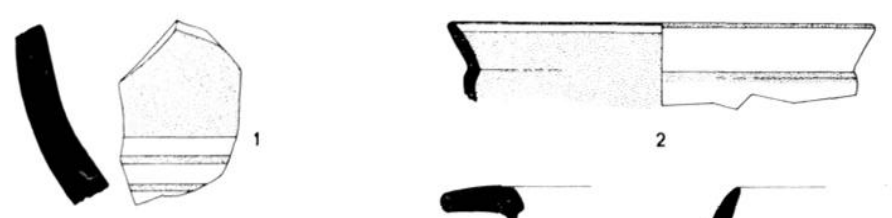

2
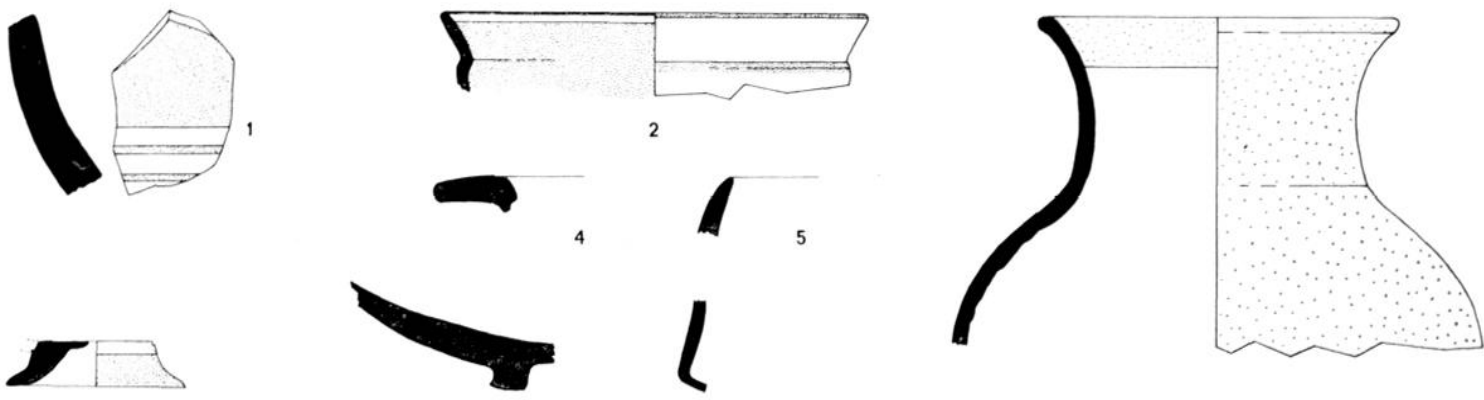

3

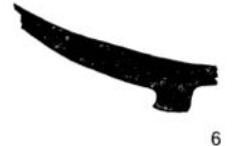

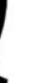

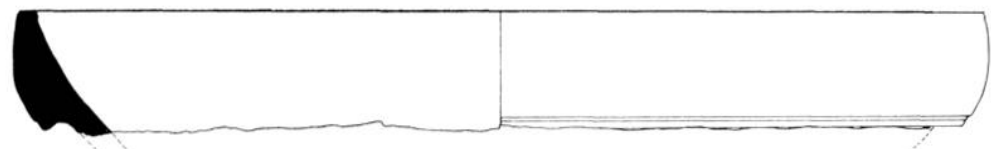

9

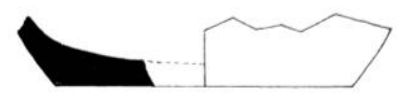

10

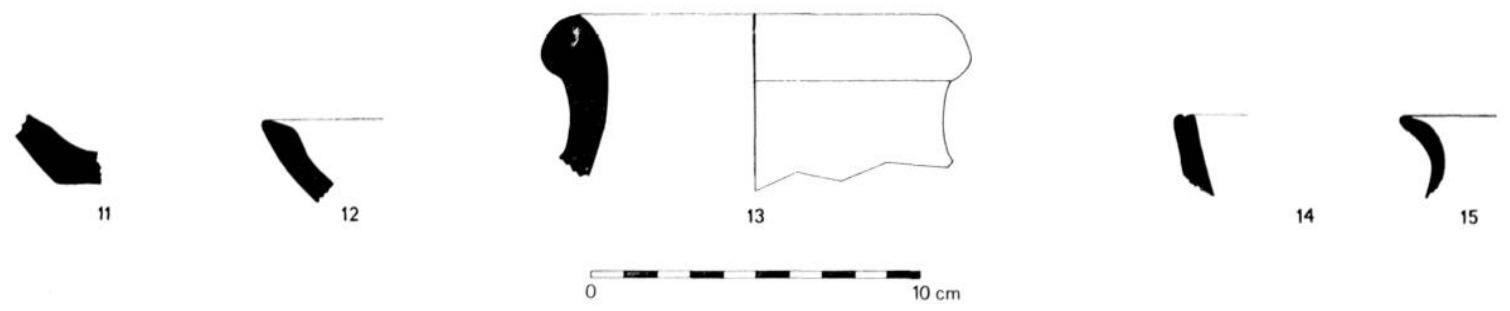

1
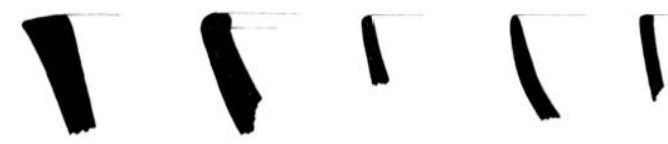

19

20

21
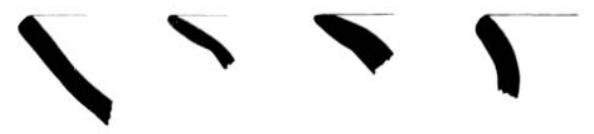

$22 \quad 23$

24

25
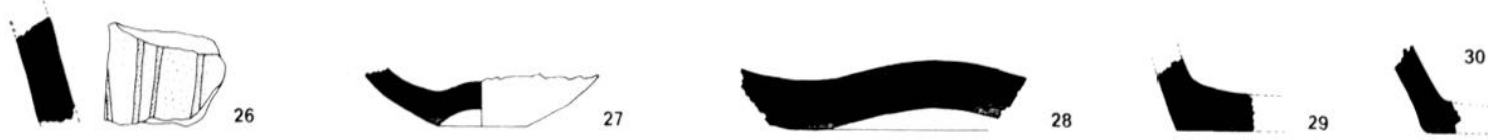

17 .laison B. Conches anterioures à liedifice.

ne représente plus que $25 \%$ de l'ensemble des céramiques fines (n 9 à 10$)$. Ses caracléristiques techniques, sont identiques à celles déjà relevées. Il en va de mème pour les formes, loujours limitées, auxquelles on peut toutefois ajouter ici le mortier;

les amphores élrusques, sont, à nouveau. Irès bien représentées ${ }^{48}$. alors que celles de lype grec sont asse\% peu nombreuses. I.es fragments massalietes. plus fréquents ici que dans l'édifice $I$. compte tenu de la proximité de la couche de destruction qui en contient beaucoup, doivent sans doute ètre considérés comme étrangers à cette strate ${ }^{49}$;

la céramique commune modelée enfin est tout a fait comparable à celle déjà sionalée. mais est plus abondante (nos 14 à:30).

In Leurs caracteristiques sonl absolument identiques a celles dejà decrites.

19 Ils representent, en tout dat de cause, moins de lo oo du nombre fotal des amphores de celle strate. 
Ciet ensemble offre le même intérêt que celui de l'édifice A. Le mobilier y est tout aussi caractéristique et on pourrait à ce sujet renouveler les remarques chronologiques déjà faites par ailleurs ${ }^{50}$. Elles permettent d'attribuer à la maison B une date de construction dans la même période entre 550 et 530 .

\section{Couche de destruclion el de nivellement de la maison $B$.}

Entre les structures à abside et la cabane indigène qui, à cet endroit, s'y surimpose, s'étend une couche d'une épaisseur de 0,15 à $0,20 \mathrm{~m}$ qui correspond au niveau de destruction de la construction. La densité de l'occupation rend ici la stratigraphie assez complexe. Cette situation tient essentiellement à une particularité de l'aménagement de la cabane indigène. Ses cloisons s'appuyent, en effet, sur un véritable "hérisson " de tessons ibériques ou puniques, fortement brûlés, plantés verticalement, assez profondément parfois, dans la couche de destruction et de nivellement de l'édifice B. Si le mobilier du sol même de la cabane a pu être isolé sans difficulté, il n'en va, évidemment, pas de même de cette fondation en céramique. La disparition de tout sol, ajoute encore à la complexité de cette strate de destruction. Sans entrer dans le détail de sa composition, - qui sera étudiée de facon complète au moment de la publication de la cabane indigène --, il convient, toutefois, de mentionner, dès maintenant, l'abondance de la céramique grise monochrome, de la vaisselle commune tournée et des amphores de type grec ou massaliète, à dégraissant de mica fin. Ces observations rejoignent celles faites dans l'édifice A et confirment que c'est bien ce type de mobilier qui est contemporain de la maison. On y relèvera l'extrême rareté des vases non tournés. L'élément le plus récent qui y a été découvert est un fragment de coupe attique de type $C$, provenant du décapage supérieur, au contact du niveau indigène, auquel il doit sans doute être restitué. (on peut cependant remarquer que, même rattaché à la couche de destruction elle-même, il interdit de placer plus bas que la fin du vi ${ }^{\mathrm{e}}$, ou le début du ve siècle, l'abandon de cette maison ${ }^{51}$.

\section{Structere circilatre (i (fig. 18).}

Sa partie centrale a été démontée afin de permettre une fouille en profondeur. Immédiatement sous les pierres se trouvait un lit horizontal de tessons qui correspond à un sol antérieur à la construction. Il est à peu près exclusivement composé de fragments d'amphores étrusques, massaliètes et de type grec. Aux premières il faut rattacher deux cols à profil en amande, évolution récente du col à bourrelet semi-circulaire qui est ici absent ${ }^{52}$ et aux dernières des cols pleins. Les céramiques fines y sont rares et le seul élément caractéristique provient d'une coupe attique du type de Cassel. Ce mobilier, dans son ensemble homogène, ne permet pas de placer cette construction avant la fin du vie siècle. Sa technique de construction, très soignée, invite cependant à la rattacher à la mème phase.

¿) Voir infra, p. 111-11:2.

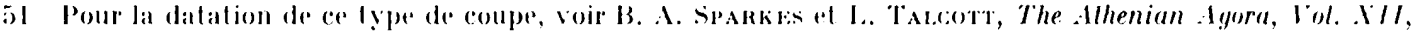
Black and plain pollery of the thth, jih and th cenluries B.C.., Princeton, 1970, p. 91-94.

52 F. Pr. II. PY, Les amphores étrusques de Vaunage, op. cil.. p. 1993-199. 

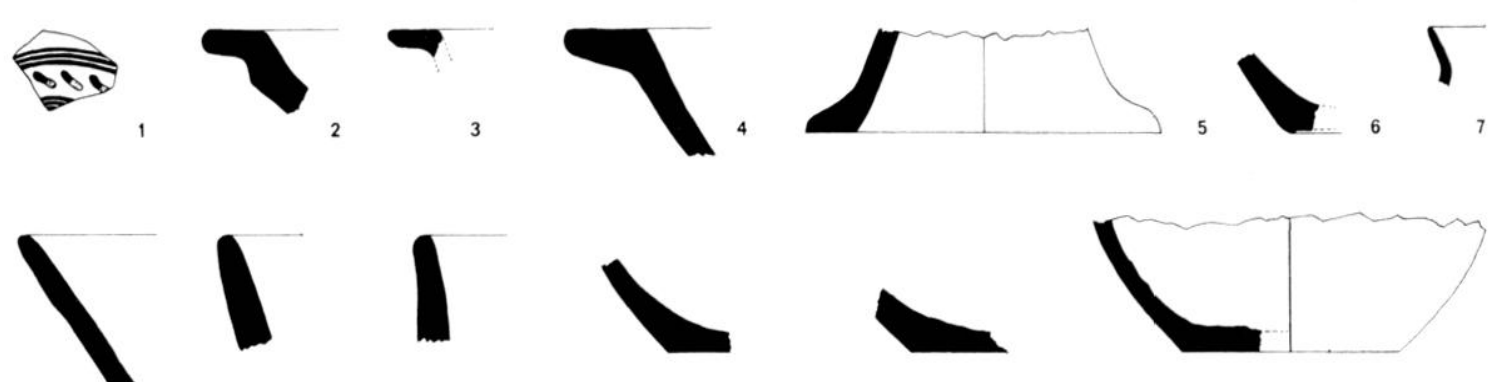

10

11

12

13
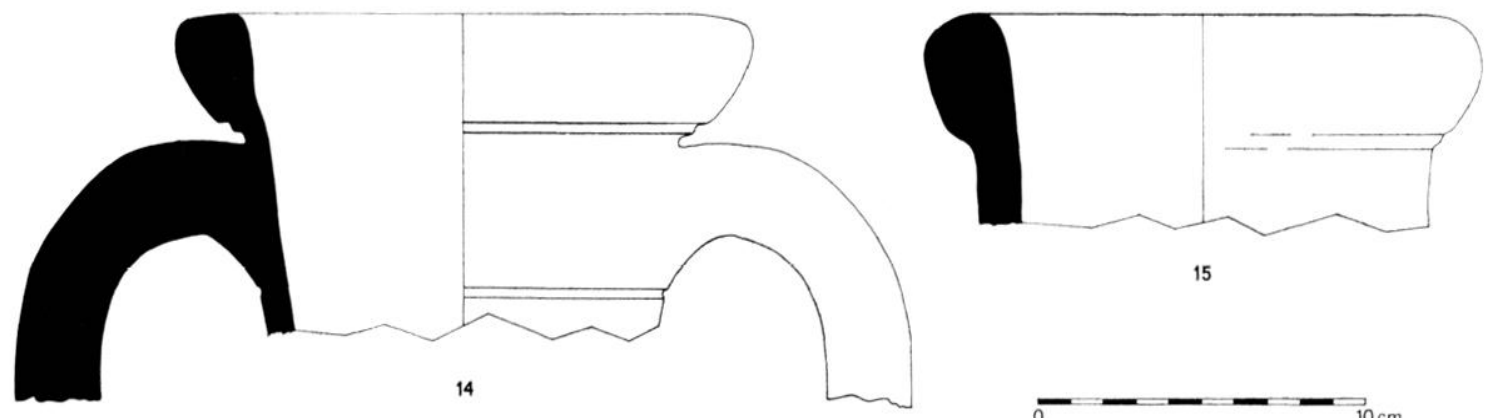

15
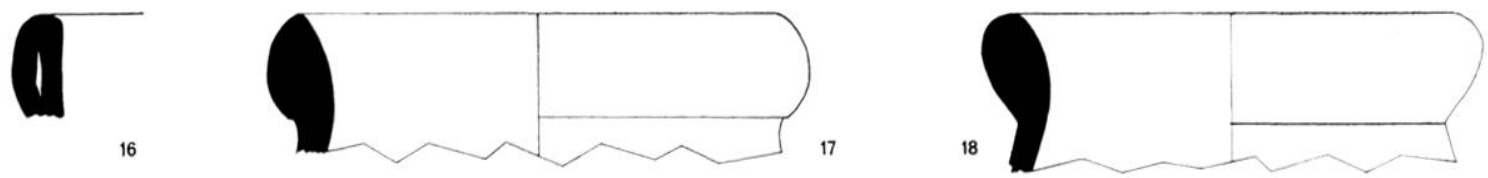

Ix Struclure circulaire. Couches anterieures a la construction.

d'occupation que les deux précédentes et à y voir l'un de ses éléments les plus récents.

L'étude de la stratigraphie des maisons A et B indique clairement, pour les deux, une date de construction voisine, sans doute dans le troisième quart du ${ }_{\mathrm{v}} \mathrm{e}$ siècle. Leur date d'abandon est plus difficile à préciser mais semble, dans les deux cas, se situer avant la fin du vi ${ }^{\mathrm{e}}$ siècle. Cne telle concordance dans l'histoire des deux édifices ne saurait être fortuite et nous aurons l'occasion d'y revenir.

\section{III. ÉtudF comparative}

La mise en cuvre d'un plan original, d'une technique de construction très évoluée, mais surtout leur datation dans le $\mathrm{v}^{\mathrm{e}}$ siècle, amènent tout naturellement à poser le problème de l'origine de ces vestiges. Lne telle recherche, pour être complète, obligerait à sortir du cadre limité fixé pour cette présentation et nous nous bornerons donc à signaler quelques exemples de comparaisons destinés, avant tout à servir de base à des investigations futures plus détaillées.

Dans un souci de clarté cette étude a été menée à deux niveaux distincts : colui du plan et celui de la technique de construction en briques crues. 
Avant de passer en revue les résultats de cette enquête, il est nécessaire d'en rappeler les limites. Les renseignements dont nous disposons pour ces périodes sont, en effet, peu nombreux et fragmentaires. La réoccupation de nombreux sites, à des époques tardives, a fréquemment bouleversé de fond en comble l'habitat préexistant, dont ne subsistent alors que de rares éléments. I cette première difficulté s'en ajoute une deuxième, liée, aux méthodes de fouilles employées, souvent plus aptes à assurer un dégagement rapide qu'une exploration minutieuse des structures. Ainsi, pour beaucoup de foulles anciennes, seuls quelques dessins, souvent imprécis et de rares photographies, permettent encore de se faire une vague idée des vestiges rencontrés. Tout en prenant en compte les limites d'une telle entreprise, il convient de rechercher si des constructions analogues à celles de Bessan sont attestées, pour les mèmes périorles, en Ciaule du sud ou, à défaut, en d'autres points du bassin méditerranéen.

\section{Gaule du sud.}

La structure des habitations en Gaule du sud au vie siècle reste très mal connue. lon certain nombre de sites fournissent cependant quelques précisions intéressantes :

A Mailhac (Aude), pour la phase II de l'oppidum du Cayla, qui correspond au vie siecle, aucun fond de cabane intact n'a encore été découvert et l'on ne possède, actuellement, que quelques angles de cases creusées dans le rocher. (on peut toutefois remarquer qu'il s'agit de cabanes rectangulaires, dont la longueur de l'un des còtés semble osciller régulièrement autour de $4 \mathrm{~m}^{53}$.

Un récent colloque a apporté quelques éclaircissements sur ce problime pour l'oppidum de Montlaurès, situé dans les environs immédiats de Narbonne. Ians ce cas, les habitations se présentent sous la forme d'encoches rectangulaires, qui entaillent très profondément le rocher et s'étagent en gradins sur les flancs de la colline. Leurs dimensions sont variables, mais toujours modestes ${ }^{54}$. La case $\Lambda$, fouillée en 1960 , avec ses $4,80 \mathrm{~m}$ de long pour une largeur de $4.35 \mathrm{~m}$. donne une asse\% bonne idée des dimensions moyennes de ces construction ${ }^{55}$.

A Ruscino, Château-Roussillon (Pyrénées-Orientales), les fonds de cabanes, attribués par le fouilleur au $v^{\mathrm{e}}$ siècle, sont également de forme rectangulaire. Leurs dimensions sont de 5,20 $\mathrm{m}$ sur $3,50 \mathrm{~m}$. Seul le réseau de trous de poteaux permet d'en reconstiluer le plan approximatif ${ }^{56}$.

A Ensérune, pour la période qui correspond au Premier Âge du Fer, ils se présentent sous la forme de plates-formes rectangulaires ${ }^{57}$, qui entaillent légèrement le tuf de la colline et dont les dimensions n'excident pas $3 \mathrm{~m}$ pour la largeur et $4 \mathrm{~m}$ pour la longueur.

Sur l'oppidum de Montfo à Magalas (Hérault), plusieurs habitations ont été dégagées au cours de fouilles récentes, encore inédites ${ }^{58}$. La superposition de vestignes d'époques différentes n'a pas permis d'individualiser les diverses phases de constructions avec la netteté qui aurait été souhaitable

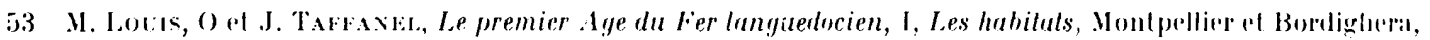
1955, p. 94 et 122.

54 J. Grny, Monllaures, fouilles de 1961, dans Bulletin de la limmmission arch. de Narbonne, p. 159-173;

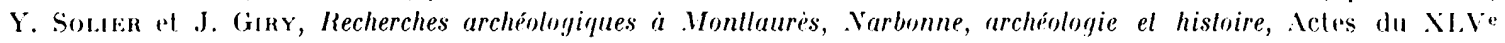
congres de la Federation historique du Languedoc mediterameen el du Roussillon, Montpellier, 1973, p. 82-90).

55 Ces cases ne sont pas datees avec précision, mais leur occupation des le ve s. parait lres vaisemblable, Y. Sollike at J. Giny, loc. cil., p. 89.

56 G. (italstres, Straligraphie de Ruscino, dans Éludes Roussillonnaises, 1951, 2, p. $145-146$.

57 J. Jaxionay, Ensérune, conlribution à létude des cirilisalions préromaines de la liaule méridionale, Paris, 1955, p. $86-87$ et pl. Xlll el Xill.

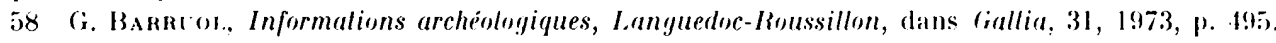


Des cabanes rectangulaires très modestes sont cependant bien attestées pour la période qui nous intéresse $\mathrm{e}^{59}$.

Le vaste habitat qui s'est développé aux Iv $^{\mathbf{e}}$ et II $\mathrm{I}^{\mathrm{e}}$ siècles avant notre ère sur l'oppidum de Pech-Maho à Sigean (Aude), limite considérablement les possibilités d'exploration des riches couches $\mathrm{du} \mathrm{rI}^{\mathrm{e}}$ siccle de ce site. Les constructions qui appartiennent à ces niveaux sonl de plan rectangulaire. mais souvent incomplètes. L'une d'elles, assez bien conservée, a une longueur de 3,40 m pour une largeur de $3 \mathrm{~m}^{\mathbf{6 0}}$.

Pour compléter ce tableau, en ce qui concerne le Languedoc occidental, il convient encore de signaler les cabanes rectangulaires de Vendres (Hérault), au lieu-dit Portal-Vielh. Les plus grandes ont là une longueur de $3,50 \mathrm{~m}$ pour une largeur de $2,40 \mathrm{~m}^{61}$. Leur présence sur ce site, antérieur aux plus anciennes importations helléniques ${ }^{62}$, mérite d'ètre tout particulièrement relevée.

Pour les oppida de Vaunage, dans l'arrière-pays de Nîmes, les recherches minutieuses, menées par $\mathrm{M}$. et F. Py, ont montré que l'apparition des structures quadrangulaires dans cette région. était liée au développement des constructions en pierre sèche à la fin du $\mathrm{v}^{\mathrm{e}}$ siècle $^{63}$. Pour les périodes plus anciennes on ne connaît que des fonds de cabanes irréguliers, en général de forme allongée, laillés dans le rocher ${ }^{64}$. Il n'est pas question de procéder au même type d'enquête pour les sites provençaux, où les renseignements dont nous disposons sont d'ailleurs bien moins complets qu'en I anguedoc. Il suffira de noter que les habitations repérées avec suffisamment de précision sont, là encore, rectangulaires, comme le montrent les quelques exemples d'Antibes ${ }^{65}$, de I a Couronne ${ }^{66}$ et de saint-Blaise ${ }^{67}$.

Cette rapide revue des principaux gisements du Languedoc et de quelques sites de Provence ${ }^{68}$, révèle qu'en aucun point de Gaule méridionale, n'ont encore été signalés des édifices comparables à ceux de Bessan ${ }^{69}$. Les habitats étudiés présentent, au contraire, un certain nombre de caractères communs qui les en distinguent très nettement. II s'agit, en effet, toujours de cabanes de plan rectangulaire, de petites dimensions, avec une longueur qui oscille régulièrement autour de 3 à $4 \mathrm{~m}$, pour une largeur de 2 à $3 \mathrm{~m}$. Aucune n'a de partic absidiale et rien ne permet de conclure à l'existence, pour ces périodes, de cloisons internes et de pièces spécialisées. Les maisons de Bessan possèdent donc un plan tout à fait original, encore inconnu en Gaule méridionale et dont il faut, sans doute,

59 Renseignement de M. J.-P. Bacou.

60 Fouille 1968, secteur $4 \times$ c, renseignement de .I. Y. Solier.

61 M. locis, O. el J. Taffaxis, Le Premier Aye du Fer languedocien, 1, op. cil., p. 1.11-14X.

62 Ce site còtier n'a, en effet, livré aucune céramique grecque.

63 M. PY, Les oppida de Vaunage, op. cil., p. 922-931.

64 Cette irrégularité est mise sur le compte de la grande dureté du substratum rocheux.

65 J.-.l. Clengtes, Fouilles de la chapelle du Saint-Esprit à Antibes (1960-1964), dans Cahiers Ligures de préhistoire el d'archéologie, XV, 1966, p. 328-338.

66 Ch. Latiraxi), Ĺn habilal côtier de l'Age du Fer à l'Arquet, à la Couronne (Bouches-du-Rhône), dans Gallia, XVII, 1959, p. 179-201.

67 H. Rollaxn, Sainl-Blaise, dans (iallia, XXII, 1964, p. 569-572 el fig. 45. Ies plans d'ensemble publies, cf. notamment .I. Eczexiat, Informalions archiologiques, Provence Côte-d Azur Corse, dans Gallia, XXV, 1967, p. 412, fig. 20, montrent que les niveaux helléniques, à colé de structures quadrangulaires, présentent quelques éléments qui semblent bien appartenir à des murs courbes. Cetle observation rendue fragile par la grande complexité des vestiges qui se surimposent les uns aux autres, si clle devait être confirmée, serait evidemment d'un tres grand intrèt pour notre propos.

68 On peut y ajouter les decouvertes de l'oppidum de Saint-Marcel au Pigute, où est signalée une cabane de la fin du vie s. Cette construction est incomplète et seule sa largeur qui esl de $2,90 \mathrm{~m}$ est conmue. Ch. I.ariraxil et J.-P. Thasmaxi, Les hubilals protohisloriques du Pigue (Drôme), Grenoble, 1973, p. 28 et fig. 6, p. 32-33.

69 Aucune allusion n’a été faite ici aux structures d’époque chalcolithique de Cambous qui, si elles présentent bien un plan absidial, semblent navoir aucun rapport avec les maisons de Bessan. A ce sujet voir en particulier: X. Gujurz, La culture de Fontbouisse, Caveirac, 1975. 
compte tenu de la position de cet habitat à proximité de la côte, chercher l'origine en d'autres points du bassin méditerranéen.

\section{Les structures absidiales dans le monde hellénique el en Italie.}

Si aucune construction de ce genre n'a encore été signalée en Gaule méridionale, ce type de plan est, par contre, assez bien attesté en terre grecque ${ }^{70}$, en particulier en Grèce de l'est, où il roisine avec des édifices rectangulaires ou ovales ${ }^{11}$. Bien que très proches par leur conception du type absidial, ces derniers ne seront pas pris en compte dans le cardre de cette étude ${ }^{72}$. De même on éliminera, bien sùr, les exemples d'époque néolithique ou minornne $e^{73}$ pour ne conserver que ceux attribués, avec certitude, aux périodes plus récentes.

Lin Cirèce de l'est, les fouilles menées par W. Lamb vers 1930 à Antissa, dans l'île de Lesbos ${ }^{74}$, ont permis l'exploration, Irès minutieuse pour l'époque, d'une intéressante série de vestiges, qui correspondent à plusieurs maisons absidiales superposées (fig. 19 a). Les restitutions qui en ont été proposées. par H. Irerup notamment ${ }^{75}$, ne sont pas absolument convaincantes car, - comme le montre l'examen attentif des relevés de coupes publiés par le fouilleur ${ }^{76}$ - elles incorporent, sans doute. des vestigres d'ensembles différents. En ne retenant que les éléments qui sont absolument sùrs, il est tout de même possible de rétablir le plan partiel d'au moins deux constructions à abside. La plus récente (fig. $19 \mathrm{~b}$ ), datée de la fin du $\mathrm{vin}^{\mathrm{e}}$ et du $\mathrm{vi}^{\mathrm{e}}$ siècle, a une longueur dans cuvre d'environ $11,00 \mathrm{~m}$ pour une largeur de $5,40 \mathrm{~m}$. La partie opposée à l'abside est fermée par un mur de refend perpendiculaire aux flancs de la maison. Lucune cloison intérieure n'est conservée ${ }^{77}$.

7) Sur ce problime de l'architecture domestique de l'épocque géométrique à l'époque archaique voir essen-

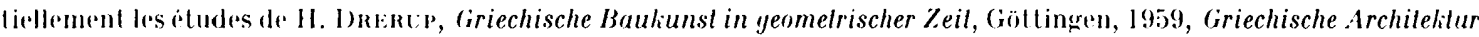
zar Zeil Homers, dans Archierol. Anzeiger, 1964, p. 180 -219 ot Zum geomelrischen Haus, dans Marburger IVinclielmann Proyramm, 1962, p 1-9; agalement S. Sixos, Die unrilassischen Ilausformen des Agäis, Hayence, 1971, avec les

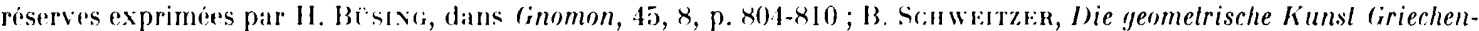

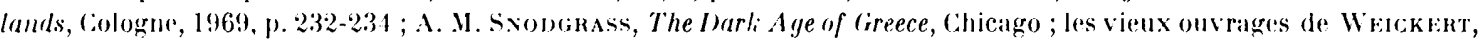
Typen der archaischen Archilelitur in (iriechenland un! Kleinasien, Augsburg, 1939, et de B. (.. RIDER, The (ireek House. Its IIisiory and developmenl from the neotithic period to the Hellenistic Age, Londres, 1916, sont maintenant largement dipasses.

71 Il faut cependanl ajouter que diverses questions concernant, entre autres, l'ivolulion, la chronologie, et les influences exactes exerceres par certains types de constructions sur d'autres, restent encore bien obscures : cf. notamment A. H. SNonerinass, The I)ark Age of (ireece, op. cil., p. 4l3. Seule la publication exhaustive des vestiges de l'architecture domestique, souvent négligée au profil de l'architecture monumentale, civile on religieuse, permetl ra de faire avancer la recherclie dans ce domaine.

72 Il ne sera donc, en particulier, pas question de la cedebre maison ovale de l'Aréopage d'Athenes, cf. W. Berre, A geomelric Itouse and a protoallic volive deposit, dans Ilesperia, 2, 1933, p. 542-640. On notera cependant avec interêt ses dimensions, qui sont de $11 \mathrm{~m}$ pour la longueur et de $5 \mathrm{~m}$ pour la largerur. Les autres exemples de maisons ovales sont donnes par H. Instrp, Griechische Bauliunst, op. cit., p. 29-31.

73 Pour les batiments de ces periodes, voir S. Sivos, Jie. Vorlitessischen Hatusformen, op. cil., p. 21-36, $81-8.3$, $8 \times, 90$ a $109-110$

74 W. LAMB, Antissa, dans Annual of the British School at Athens abrege : A.B.S.A., XXXII, 1931-1932, p. $41-67$.

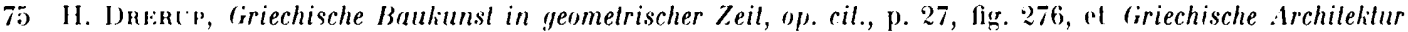
:ur Zeil Homers, op. cit., p. 186, fig. 25.

76 W. LAMB, np. cil., p. 43. II n'est sans doute pas inutile d'insister sur la qualite tout à fait exemplaire des illustrations de cette publication.

77 Celte absence ne doit pas trop surprendre. Si, comme semble le supposer W. lamb, l'élévation de ces maisons blait effectuée en briques crues, il est vraisemblable que les cloisons intérieures utilisaient le même matériau. L'absence comme à Bessan, d un soubassement en pierre, suflisant alors à expliquer leur totale disparition. 

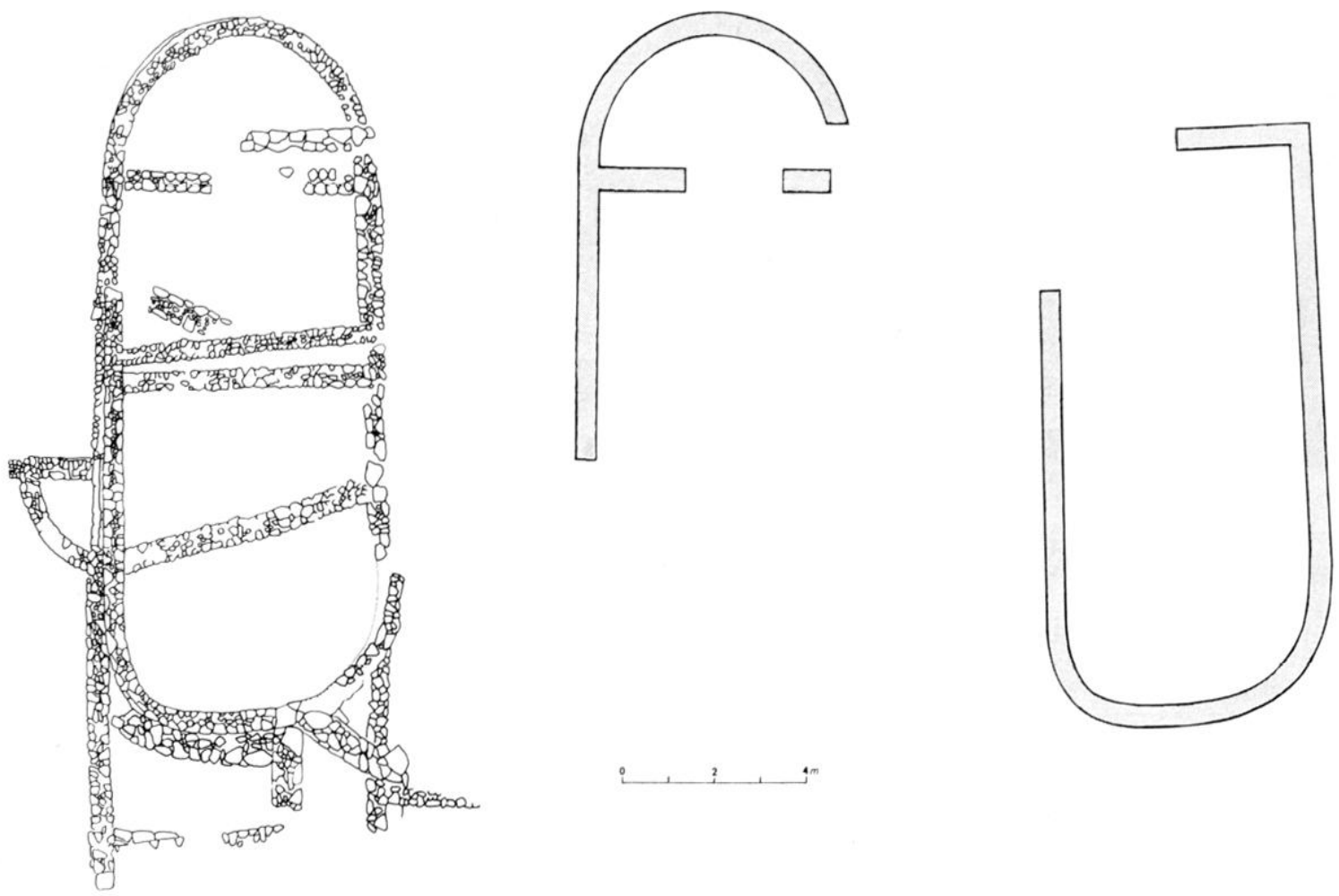

19 Iosbos, Mulissa. Maisons alosidiales dapres $\mathbf{W}$. Lamb.

Les murs. d'une largeur de 0.00 m sont tris soigneusement appareillés. Ils se surimposent à un bâtiment à abside plus ancien. daté dans la premiere moilié du vine siócle, dont le plan, si l'on s'en tient aux éléments aftribuables avec certitude a cet ensemble, est bien moins complet (fig. $19 \mathrm{c}$ ). sa largeur est de $1.90 \mathrm{~m}$. L'abside, d'une profondeur de $2,70 \mathrm{~m}$ présente ici, a la différence de la précédente. une courbure continue. (On nolera avec intérêt l'existence d'un mur de refend, séparant la parlie absidiale de la salle avanl. I a longueur de cette derniere ne nous est pas connue, mais est supérieure a 5,30 m, re qui donne une construction dont la longueur totale dans ceuve, doit largemeal dépasser 9.00 $\mathrm{m}$. Ians ce cas nous ignorons la forme de la parlie opposée a l'abside. La aussi, l'épaisseur des murs varie entre 0. fi) et (0.5) $\mathrm{m}$.

En Grice de l'est encore, a Bayrakli, au centre de la còle ouest de la Turquie, les fouilles anglolurques ${ }^{78}$. menées au lendemain de la deuxiome guerre mondiale. ont permis d'explorer un important. secteur du sile antique de smyrne. In cerlain nombre de niveaux d'occupation. qui s'étendent. de l'époque prologéométrique à la période hellénistique, y ont élé dégagésa. L'existence, pour rhacune de ces phases. d'abondants vestiges de constructions, en général tres bien conservés, ronfire a ces fouilles un intérèt exceptionnel. Une double couche, at tribuéc à l'époque géométrique

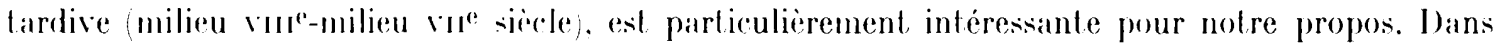
re niveau. en eflel. a rote de struclures quadrangulaires, ont élé découvertes plusieurs maisons absidiales, en lous points comparables à relles de Bessan. Gess édifices nont malheureusement pas encore lait l'objet d'une publication détaillee et nous ne disposons actuellement que d'un plan

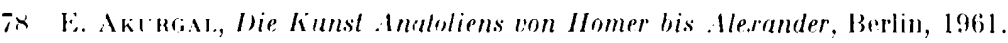

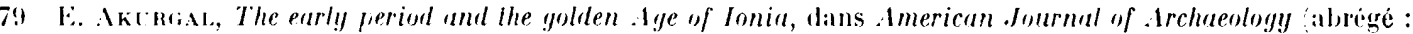
A.J.A., , 66, 196:), р. 3699-379. 
d'ensemble à trop grande échelle ${ }^{80}$. Plusieurs bâtiments à abside, de taille variable, y apparaissent cependant très clairement ${ }^{81}$. I eur largeur s'établit régulièrement autour de $3,50 \mathrm{~m} \dot{\mathrm{a}} 4,50 \mathrm{~m}$ et la longueur, lorsqu'elle est connue, approche fréquemment 8 a $10 \mathrm{~m}^{82}$.

Dans la même couche de la première moitié du vil ${ }^{\mathrm{e}}$ siècle, ont été dégagés les restes d'une construction semi-soulerraine, d'un diamètre d'environ $3,20 \mathrm{~m}$, dans laquelle on a reconnu une tholos ${ }^{83}$. C'est peut-être à ce type d'ouvrage, silo aérien ou réserve quelconque, qu'il faut rattacher la struclure circulaire de Bessan, dont les dimensions sont comparables ${ }^{84}$.

A Perachora, sur le golfe de Corinthe, le sanctuaire de Hera Akraia, daté au vir ${ }^{e}$ siècle, présente un autre exemple du mème type de plan ${ }^{85}$. Le mauvais état de conservation des vestiges, endommagés par de fortes pluies avant qu'un relevé de détail ait pu être effectué, ne permet pas de connaître avec précision ses dimensions ${ }^{86}$. Les murs ont une épaisseur de $0,70 \mathrm{~m}$ et sont assez grossièrement appareillés. Il n'y a aucune trace de séparation entre l'abside et la partie droite.

D'autres bâtiments à abside, pour lesquels nous ne disposons cependant que de renseignements incomplets, ont été signalés à Delphes ${ }^{87}$, Éleusis ${ }^{88}$, Érétrie ${ }^{89}$, Ieukanti ${ }^{90}$, Mycènes ${ }^{91}$, Solygreia ${ }^{92}$ et Argos ${ }^{93}$. Parmi les découvertes récentes, celle de Mélie ${ }^{94}$, en raison à la fois de l'originalité de sa conception et de sa dalalion dans l'époque archaïque, mérite de retenir plus particulièrement. notre attention. Sion plan est celui d'une maison à abside dont le passage du mur de refend, opposé a l'abside, aux murs latéraux, au lieu de se faire à angle droit, s'effectue par l'intermédiaire de. tronçons courbes ${ }^{95}$.

En Italie ${ }^{96}$ enfin, ce type de construction n'est pas non plus inconnu et les fouilles récentes

8) R. V. Nicholas, Old Smyrna, the Iron Age fortifications and associated remains on the cily perimeler, daus A.B.S.A., 53-54, 1958-1959, p. 35-137.

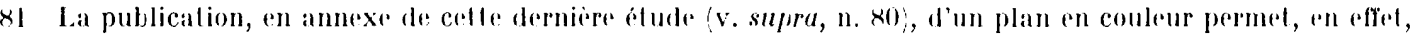
de très bien distinguer les différentes peiriodes.

82 E. AKURGal, op. cil., p. 12-13, note 55.

83 Idem, p. 301, fig. 2.

84 Le principal argument en falcur de cette interpretation est le soin même apporté à l'appareillage de cette construction. On a, en outre, pu constater que les gros blocs étaient rigulièrement disposés à la périphérie alors que le centre était occupé par des blocs de dimensions plus modestes. si, comme l'ont montré les sondages, cette construction correspond bien a un soubassement, ce type de dispositif ne peut s'expliquer que par l'existence. en ilcvation d'un mur circulaire en briques crues qui vient prendre appui sur les blocs extérieurs. La reconstruction effectuée par R. V. Nicholls pour la tholos de Smypne, cf. E. $\Lambda$ ktirciar, op. cit., p. 301, fig. 2, donne une assez bonne idee de la facon dont pourrait se presenter ce petit edifice. L'absence a Bessan d'une partie souterraine est sans doute à mettre en rapport avec la nature géologique de la trrasse qui ne se prête pas au surcreusement.

85 H. Payxe, Perachora, the sanchuaries of Hera Aliraia and Limenia, I, Oxford, 19.10, pl. 116.

86 Ibidem, p. 29.

87 II. DRERUP, (iriechische Bauliunsl, op. cil., p. 26.

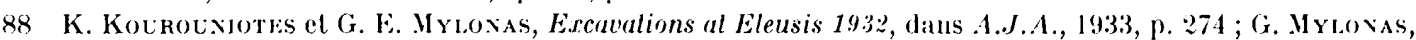
Eleusis and the Eleusinian Mysteries, Princeton, 1961, p. 56-60.

89) H. DRERT:P, op. cil., p. 27.

90 S. Sivos, Die Vorklassischen IIausformen, op. cil., p. 109.

91 (i. Davx, Chronique des fouilles el découverles archéologiques en Girice, 1962, dans Bull. Correspondance Hellénique, 1963, p. 746.

92 H. DRFRUP, op. cit., p. 29.

93 A. M. S.vodgrass, The Dark Age of Greece, op. cil., p. 409.

94 G. Kleixer, P. Hommis et W. Mulder-Wisener, Panionion und Melie, 23. Ergänzungsheft zum Jahrbuch des Deutschen Archäologischen Instituts, 1968, p. 116 et s.

95 C'est sans doute également à ce type qu'appartient une partie d'édifice découverté à Naxos, S. Sıxos, Die Vorklessischen IIutusormen, op. cil., p. 110. Leur prototype commun est la célebre maison de Bayrakli, datée de la fin du $x^{2}$ s. ou du $1 x^{e}$ s., qui présente une structure assez voisine, cf. E. Aktrgal., Ancient civilizalions and Rains of Turkey, Istanbul, 1970, pl, $41 \mathrm{c}$.

96 lá aussi on ne prendra en comple que les véritahles batiments à abside en excluant les cabanes ovales de l'Age du Fer, notamment celles, bien connues, de San Giovenale en Étrurie, cf. A. Bolernus, Elruscan Cullure, New York-Malmoë, 1962, p. 28; K. HAxes.., The escavalions of the Swedish Instilute in Rom in san Giovenale and ils environs, Elruscan Cullure, op. cil., p. 289-312. 
d'Ischia, au largere de Naples, sur le site du plus ancien établissement grec d'Occident, ont livré plusieurs maisons à abside datées du vin ${ }^{\mathrm{e}}$ siécle ${ }^{97}$.

Cette rapide enquête, sans être exhaustive, montre cependant clairement la parfaite similitude de plan, mais aussi de dimensions ${ }^{98}$, existant entre les habitations d'époque gréométrique ou géométrique tardive du monde grec et les édifices de Bessan. Le principal probleme, mais aussi l'un des intérèts majeurs de cette découverte, est celui de la datation basse de ces derniers. Comme nous l'arons vu. leur construction ne saurait remonter all-delà du milieu du vi $\mathrm{e}^{\mathrm{e}}$ siècle, alors que les prototypes appartiennent, dans leur grande majorité, aux vine of vile siècles. Ils prennent donc rang parmi les plus récentes maisons de re type. a la suite directe de celles de Bayrakli du milieu du vir ${ }^{\mathrm{e}}$ siècle ${ }^{99}$.

\section{LA TE:HNOCE DE coNSTRETTON.}

Les quelques restiges de cabanes du Premier İge du Fer que nous possédons en Ciaule méridionale trahissent une conception tres simple, liée à l'utilisation de modestes doisons de torehis at de clayonnages, formées de branchages et de roseaux entrelacés, noyés dans de l'argile. Cette trame serrée prenait appui sur un réseau de poteaux, disposés sur tout le pourtour de la cabane, à peu de distance les uns des autres ${ }^{100}$. Quelques petits fragments de torchis portant les empreintes circulaires de l'armature végétale sont, avec les traces d'implantation des pieux, les seuls témoins de ces constructions. İ côté de ce système, qui semble être celui utilisé dans la quasi-totalité des cas au cours du vi ${ }^{\mathrm{e}}$ siècle, on signale plus rarement la découverte de briques crues. Si, comme le montrent les récentes fouilles de Martigues ${ }^{101}$, leur utilisation commence à être bien attestée dans certains secteurs de la zone littorale aux IV et III $^{\mathrm{e}}$ siècles, dans un contexte du vi ${ }^{\mathrm{e}}$ siècle elle reste rare ${ }^{102}$. En Languarloc-Roussillon on ne peut guère citer que les cas du poste fortifié de Pech-Maho à sigean, où un important tronçon de mur en briques crues daté du vie siècle est conservér â de l'oppirlum de. Montfo à Magalas ${ }^{104}$, où des vestiges de ce type semblent devoir ètre attribues à la même epoque ${ }^{105}$. Jamais cependant, n'a été mentionnée la présence de briques crues en place sur un soubassement en pierre très régulier, comme

97 (․ Bucmisk, Recent worli at Pithehoussai (Ischia) 196.j-1971, dans Archaeological Reports for 1970-1971, p. 6.1-66, fig. 5.

98 Particulierement remarefuable comme nous lations vu dans le cas de I.esbos.

99 (On peut dailleurs noter que la masson de Bessan, du fait de l'apparition de pieces specialisees, marque un net progres dans lomeranisation interne par lapport a celles de Bayrakli, où un semblable amenagement ne semble pas

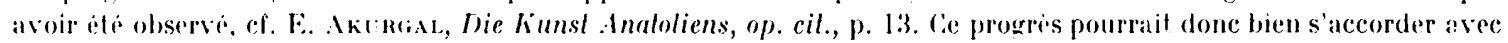
la dalation hasse de ces verstigres.

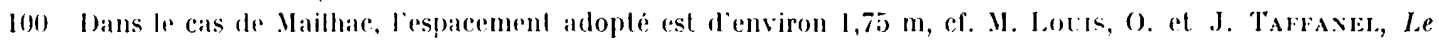
I'remier Age du Fer lan!luedocien, op. cit., I, Les habilats, p. 94.

II) F. SAlviat, Informations archéologiques, Provence, dans Gallia, 30, 1972, p. 524-525.

10:2 Leur utilisation sur certains sites de Provence comme Teste Négre ou loppidum de la cloche aux PennesMirabeall se place également a une époqur tardive, cf. F. Sasiat, op. cil., p. 5l9-5:20.

1033 (;. Bannoor., Informalions archólogiques, Languedoc-Roussillon, dans Gallia, XXIX, 1971, p. 377.

10.4 Benseignement de .I. J.-P. Bacoul.

115) I Bessan mème J. (iry a signalé la présence de briques crues, cf. Tell de La Monédière, op. cil., p. 27, mais aucune indicalion concernant leur forme on leurs dimensions n'a iete constriar. 
c'est le cas à Bessan et c'est à nouveau vers le monde hellénique qu'il faut se tourner pour trouver une technique de construction comparable.

L'architecture de briques crues ${ }^{106}$ a, en effot, de tous temps connu un succes considérable dans ces régions, comme en font foi les nombreuses mentions littéraires et épigraphiques, où abondent les précisions sur la technique de fabrication et l'utilisation de ce matériaut ${ }^{107}$. Vitruve, dans le passage consalcré à ce mode de construction, opère une distinction très nette entre les briques crues carrées, qu'il dit utilisées par les (ireces et le type rectangulaire. appelé lydien, encore couramment employé par les Romains à l'époque augustéenne ${ }^{108}$. Cette distinction est en fait ancienne et Vitruve n'a fait là que reprendre la tradition hellénique. Cies différences de formes et de dimensions semblent recouvrir une evolution chronologique. Alors que la brique carrée a connu une grande faveur dans le monde gree au $v^{e}$ et surtout aux Ive $^{\mathrm{e}}$ et III $^{\mathrm{e}}$ siècles, le type lydien semble être préféré aux époques antérieures ${ }^{109}$. Déjà utilisé par les constructeurs mycéniens, il est également bien altestí en Grèce de l'est du $\mathrm{x}^{\mathrm{e}}$ au vire siècle. Les renseignements dont nous disposons pour l'époque archaïque sont, en revanche, bien plus minces ${ }^{110}$. Compte tenu des problemes de conservation de ce matériau, il convient de ne pas y attacher d'importance particulièrer11. Parmi les rares sites qui, comme Bessan, ont livé des briques crues diatables avere certiturle dans le vie siècle, le plus intéressant est, à nouveau, Bayrakli où un modèle dre briqure. d'une longueur de $0,45 \mathrm{~m}$ pour une largeur de $0.30 \mathrm{~m}$, absolument identique à colui de Bessan, a été employé dans une maison du milieu du ve sièce ${ }^{112}$. D'autres encore, de dimensions très voisines, ont été utilisées dans un tronçon de rempart de la deuxième moitié du vir ${ }^{\mathrm{e}}$ siècle $^{113}$.

Des possibilités de comparaison sont également fournies par l'Étrurie, où des découvertes récentes montrent que les maisons étrusques, en élévation, étaient également constituées de briques crues ${ }^{114}$. I Roselle, Rusellae, ont notamment été dégagés plusieurs

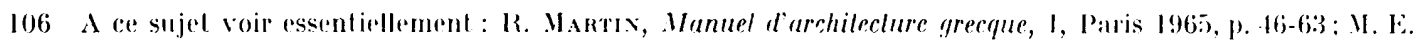

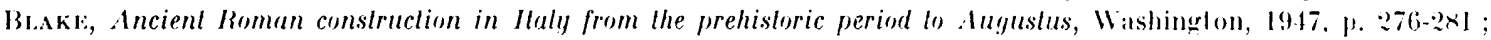
R. V. Nicuoros, Old Smyrna, the Iron dge forlificalions and associated remains on lhe cily perimeler, dans A.B.S..1.,

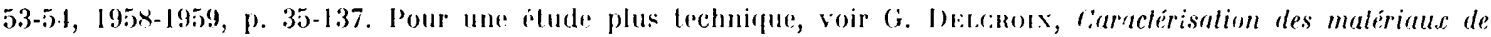

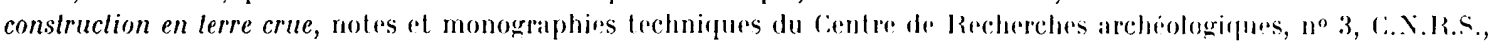
Paris, $197:$.

107 R. МАнтіх, Manuel d archileclure, op. cil., p. इ $8-63$.

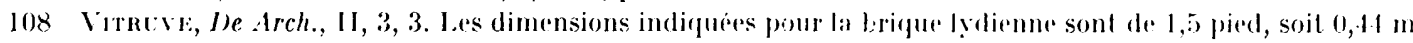
pour la longurur et I pied, soit $30 \mathrm{~cm}$, po:ar la largeur.

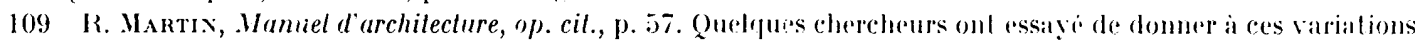
de dimensions une valeur chronologique assez précise. Voir a ce sujed les tries interessantes remarques de li. V. Nicholls, architecte de la mission anglaise a Bayrakli, Old smyrna, the Iron Age forlificalions..., op. cil., p. 100 - lo6.

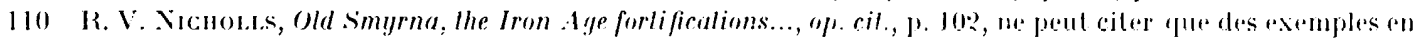
provenance d'Eleusis.

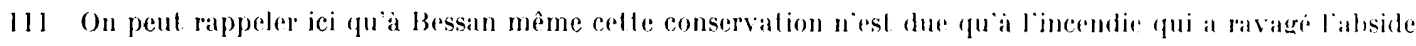
de la maison $A$ et provorue ainsi une recuisson partielle de certaines brigues. I.a presence deume reurele de lerre plus argileuse dans le voisinage des structures est souvent le seul vestige qui subsisto de ces murs.

112 K. V. Nicholas, Old Simyrna, the Iron Age fortifications..., op. cit., p. I03.

113 I Jun point de vue technique, cest egalement arec les const puctions de Bayrakli dgue les maisons de Bessan présentent le plus d'aflinites. Le recours a un soubassement de petils galets noyés dams de l'alerile, suivant un sysleme

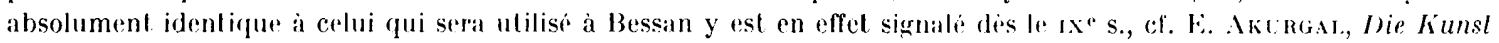
Anatoliens, op. cil., p. $\mathrm{x}-13$.

114 Ce probleme de l'elevition des maisons etrusques a ete a lorigine d'àpres polimiques auxquelles les 
troncons de murs, certains conserves sur une hauteur de près de $1.30 \mathrm{~m}^{115}$. Datés de la fin du vir et des débuts du vi ${ }^{\mathrm{e}}$ sièle, ils sont élevés à l'aide de briques lydiennes dont Jes dimensions, variables, sont, an grénéral, de $0,44 \mathrm{~m} \times 0,29 \mathrm{~m} \times 0,08 \mathrm{~m}$ à $0,12 \mathrm{~m}$ pour l'epaisseur116. W'autres briques, toutes sensiblement du mème modèle, ont encore été signalese an divers points d'Étrurie, a Pyrgi, Vetulonia, Perrugia et a Fiesole ${ }^{117}$, mais leur datation précise n'est pas toujours connuerene .11 n'est sans doute pas inutile de préciser que cette relative abondance du type lydien, à liusellae notamment, tend, de plus en plus, à ètre presentée comme un témoignage des rapports anciens existant entre l'Etrurie et la Merditreranée orientale119.

Cette eturle des techniques de construction montre que, la encore, cest le monde hellenique, la cirèce de leest en particulier, qui offre les meilleures possibilités de comparaisons.

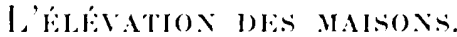

Lal grande ressemblance des maisons de Bessian avec des édifices de Grece ou de Grèce de l'est permet d'onvisager. aver plus de facilité, le probleme de leur restitution en blévation. Xous disposons, an effet, pour ces régions, de véritables modeles réduits de constructions, offerts en ex-roto dans les sanctuaires. Éxécutés le plus souvent en terre culte, ils fournissent de précieux renseignements sur l'aménagement des habitations dont ils sont la réplique. Parmi ceux représentant des maisons absidiales, les plus utiles proviennent l'un de simmos et l'autre de P'erachora' ${ }^{121}$. Bien que de facture différente, ils donnent sans doute une assez l,onne idée de la façon dont se présentaient, de l'extérieur, les maisons de Bessan. Tous deux possedent un toit à double pente, assez raide, qui déborde largement sur les murs ${ }^{122}$. Quelques détails dans l'exérution de la toiture impliquent

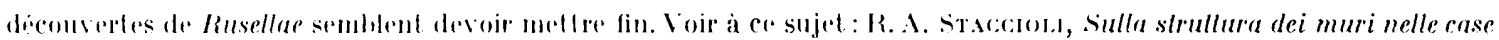

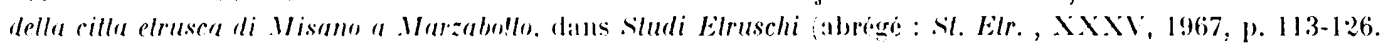

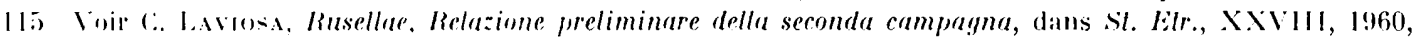

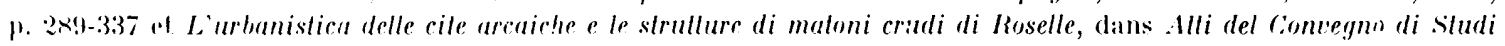
sulia ci!la elrusca el ilalica preromana, Bolosme, 1970, p. 109-216.

116 1.. lavoss, Rusellae, Relazione preliminare della seconda campa!ma, op. cil., p. 31.1-315 el Rusellae, Relazione pre!iminare della ler:a campa!mn, dans . 1. Eir., XXIX, 1961, p. 11.

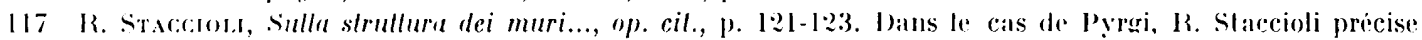

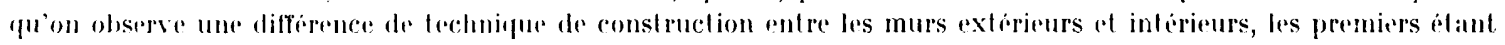
beves sur une fondation dre pieres, les seconds plus minces, reposant directement sur le sol. leet te disposilion correspond tres rexactement a celle de la matison a de Bussan.

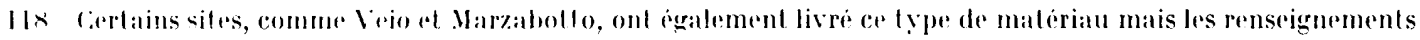
doul nous disposons dans res ras sont trop incomplets pour pute ces vestiges puissent itre pris en considemalion ici.

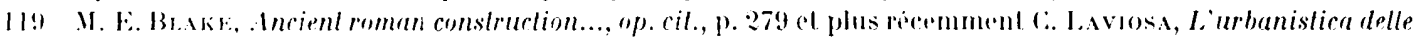
rille arraiche..., "p. cil., 1. :216.

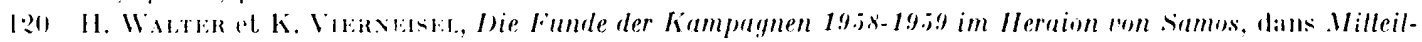

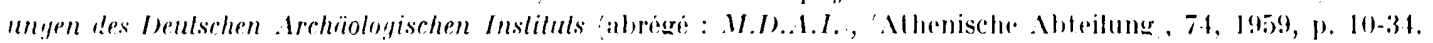

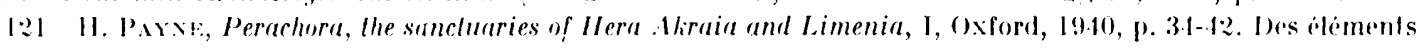

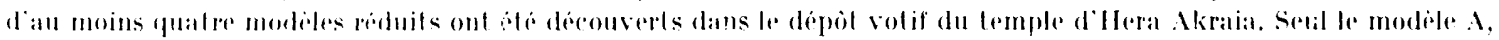

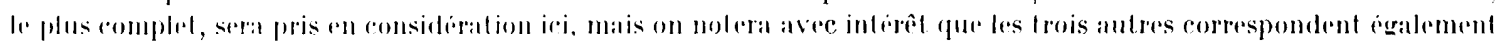
i des maisons albsibiales.

1.22 Ce parli d an toil se developpant largement an-dela des murs exterieurs de la maison decoule de la necessite

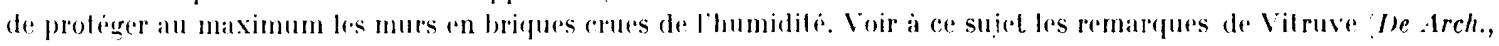

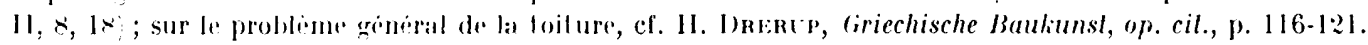


clairement, pour les originaux, une couverture de chaume ou de roseaux ${ }^{123}$. Dans les deux cas, l'accès à l'édifice est aménagé dans le mur opposé à l'abside et c'est sans doute rette solution qui a également été adoptée à Bessan, où la destruction de la partic sud de la construction nous prive malheureusement de toute indication à ce sujet.

On notera enfin que certains de ces mo-

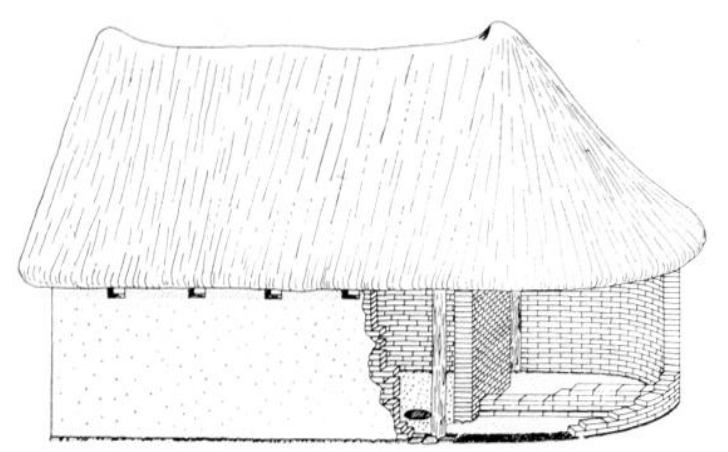

:1) La Monedierre Essai de restitution de la maison .1. dèles, celui de Perachora notamment, prouvent, de façon indiscutable, que ces bâtiments etaient munis de veritables fenètres, qui se présentent sous la forme d'orifices triangulaires, on carrés, aménagés immérliatement sous le toit. Certains s'ouvrent en façarle all-dessus de la porte. La disparition de la partie sud de l'édifice rend toute reconstruction graphique des maisons de Bessan hypothétique. Les observations de détail qui ont pu être faites au cours de la fouille. les indications des modèles votifs et les solutions adoptées pour les édifiees de Bayrakli124 at de Perachora ${ }^{125}$. permettent, néanmoins, une restitution assez précise de l'arrière de la maison $\Lambda^{126}$ qui. si elle reste partielle, n'en donne pas moins une assez bonne ideer de la conception d'ensemble de l'ouvrage ${ }^{127}$ (fig. '20).

La conclusion de ce qu'on vient de lire s'impose done d'elle-même. Bitrangères, fomme nous l'avons vu, à tout ce que nous connaissons pour la mème époque en Giaule du surl, ces structures, qui présentent tout à la fois un plan et une technique le construrtion bien attestés en Véditerranée orientale doivent, très vraisemblablement, correspondre à des maisons grecques. Leur présence dans la basse vallée de l'Hérault dans la deuxième moitié du vi siècle, sur ce site précédemment occupé par des populations indigènes, est évirlemment d'un très grand intérêt et nous aurons l'occasion d'y revenir plus en détail dans le carlre d'un travail d'ensemble, consacré à l'étude des relations entre Grees et indigènes dans cette région ${ }^{128}$. On peut cependant noter, dès maintenant, que cette découverte éclaire d'un jour nouveau l'un des problèmes les plus difficiles posés par la colonisation phocéenne en Languedoc: celui de l'occupation antique de l'Agadès. Si elle ne fournit aurun renseignement précis sur la date même de fondation du comptoir grec d'Agde elle prouve, en effet. de façon indiscutable que des populations grecques étaient établies dans la basse vallée de l'Hérault dès le milieu du vi $\mathrm{e}^{\mathrm{e}}$ siècle.

André Nickliss.

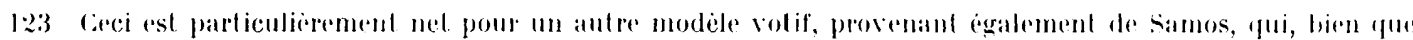
de forme ovile, présente les mèmes tojts que les exemplaires a absidr, cf. E. Bıscuor, Heraion ron samos, frühe

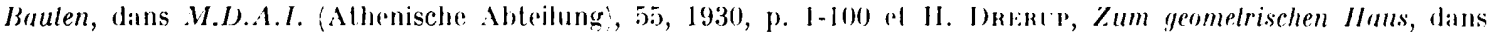
Marburger Winclielmann Program, 1962, p. 1-9.

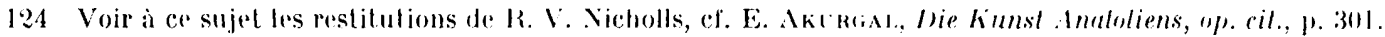

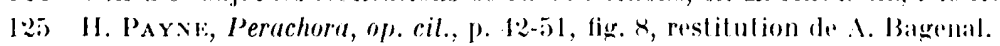

126 Dans le cas de Bessan, a la difference de Bayrakli et de Perachoral, on nole l'atsence de poleall central, remplacé ici par un mur de refend puissant, séparant l'atside de la partie avant quadrangulaire.

127 Le même type d'aménagement se retrouse encore dans la chammicre de tamargue. Voir a ce sujet $\mathrm{F}$. Brxort, Les "chaumieres à abside" de la Camargue, dans Revue du follitore Franrais, 1933x, p. 18-20).

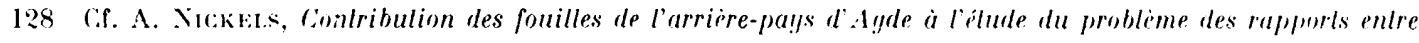
Cirecs al indigines en Languedoc ( $I^{\prime}$ e et $V^{\mathrm{e}}$ siècles), à paraitre. 